\title{
Tailoring stimuli-responsive delivery system driven by metal-ligand coordination bonding
}

\author{
This article was published in the following Dove Press journal: \\ International Journal of Nanomedicine \\ 26 April 2017 \\ Number of times this article has been viewed
}

\author{
Hongshan Liang ${ }^{1-3}$ \\ Bin Zhou ${ }^{4}$ \\ Yun $\mathrm{He}^{1-3}$ \\ Yaqiong Pei ${ }^{1-3}$ \\ Bin $\mathrm{Li}^{\mathrm{I}-3}$ \\ Jing $\mathrm{Li}^{1-3}$ \\ 'College of Food Science and \\ Technology, Huazhong Agricultural \\ University, ${ }^{2}$ Key Laboratory of \\ Environment Correlative Dietology, \\ Huazhong Agricultural University, \\ Ministry of Education, ${ }^{3}$ Functional \\ Food Engineering \& Technology \\ Research Center of Hubei Province, \\ Wuhan, Hubei, ${ }^{4}$ College of Food \\ Science and Technology, Shanghai \\ Ocean University, Lin Gang New City, \\ Shanghai, People's Republic of China
}

Correspondence: Jing Li

College of Food Science and Technology, Huazhong Agricultural University,

Wuhan, Hubei 430070, People's

Republic of China

Tel +86 2763730040

Fax +86 2787288636

Email lijingfood@mail.hzau.edu.cn

\begin{abstract}
In this study, a novel coordination bonding system based on metal-tannic acid (TA) architecture on zein/carboxymethyl chitosan (CMCS) nanoparticles (NPs) was investigated for the $\mathrm{pH}$-responsive drug delivery. CMCS has been reported to coat on zein NPs as delivery vehicles for drugs or nutrients in previous studies. The cleavage of either the "metal-TA" or " $\mathrm{NH}_{2}$-metal" coordination bonds resulted in significant release of guest molecules with high stimulus sensitivity, especially in mild acidic conditions. The prepared metal-TA-coated zein/ CMCS NPs (zein/CMCS-TA/metal NPs) could maintain particle size in cell culture medium at $37^{\circ} \mathrm{C}$, demonstrating good stability compared with zein/CMCS NPs. In vitro release behavior of doxorubicin hydrochloride (DOX)-loaded metal-TA film-coated zein/CMCS NPs (DOX-zein/ CMCS-TA/metal NPs) showed fine $\mathrm{pH}$ responsiveness tailored by the ratio of zein to CMCS as well as the metal species and feeding concentrations. The blank zein/CMCS-TA/metal NPs (NPs-TA/metal) were of low cytotoxicity, while a high cytotoxic activity of DOX-zein/ CMCS-TA/metal NPs (DOX-NPs-TA/metal) against HepG2 cells was demonstrated by in vitro cell assay. Confocal laser scanning microscopy (CLSM) and flow cytometry were combined to study the uptake efficiency of DOX-NPs or DOX-NPs-TA/metal. This system showed significant potential as a highly versatile and potent platform for drug delivery.
\end{abstract}

Keywords: coordination bonding, $\mathrm{pH}$-responsive, high stimulus sensitivity, drug delivery

\section{Introduction}

Stimuli-responsive systems provide a variety of promising applications in biotechnology and the crafting of smart materials, which are of particular interest in the design of drug delivery vehicles. ${ }^{1-4}$ The release of guest molecules can be tailored using their responsiveness to external stimuli such as $\mathrm{pH},{ }^{5-9}$ temperature ${ }^{10}$ and light. ${ }^{1-13}$ Among these stimuli-responsive systems, the $\mathrm{pH}$-sensitive system is of vast interest because of the acidic microenvironment in solid tumors, which is very different compared with the normal tissues. ${ }^{14,15}$ Thus, a finely designed $\mathrm{pH}$-sensitive transporter can release its payload when passing through a low-pH region, while it can maintain its property under physiological conditions. ${ }^{16,17}$

Self-assembled biodegradable nanoparticles (NPs), on the base of natural polymers, have attracted considerable attention for drug delivery systems, because of the enhanced absorbability and low toxicity in the degradation of end products. ${ }^{18-20}$ Common routes for $\mathrm{pH}$-responsive systems based on natural polymers include the swelling/deswelling effect of the NPs and changes in the electrostatic interaction between the components when changing the $\mathrm{pH}$ value. ${ }^{21,22}$ Recently, the forces to impact the $\mathrm{pH}$ response are focused on metal-organic coordination bonding. The formation and breakage of coordination bonds are achieved by $\mathrm{pH}$ changes, which gives the possibility to use metal-organic coordination materials for constructing an advanced $\mathrm{pH}$-responsive drug delivery system. ${ }^{23}$ 
Tannic acid (TA), a high-molecular weight polyphenol, contains five digalloyl ester groups covalently attached to a central glucose core. ${ }^{24}$ The unique structure of TA can help in interacting with a variety of materials through multiple reaction pathways. ${ }^{24-27}$ Like many other polyphenols, a salient feature of TA is its strong metal chelation ability and material surface-binding affinity, by which it acts as a polydentate ligand for metal ion coordination bonding. ${ }^{28,29}$ Due to diverse structural and functional properties of TA, combined with its chelation ability, metal-TA coordination complexes could form three-dimensional films on a range of substrates. ${ }^{30,31}$ The cleavage of the coordination bonds based on metal and TA is sensitive to variations in external $\mathrm{pH}$, which could impact the delivery system by the $\mathrm{pH}$-responsive release of the drug under acidic conditions. In our previous work, we have investigated designable coordination bonding-based metal-TA architecture on zein NPs. ${ }^{7}$ However, we would further like to explore a more powerful $\mathrm{pH}$-responsive system with high stimulus sensitivity, especially in mild acidic conditions.

Carboxymethyl chitosan (CMCS), a derivative of chitosan, is widely used for biomedical applications. In previous studies, CMCS was coated on zein NPs and used as a novel delivery system for drugs or nutrients. ${ }^{32,33}$ Thus, we would like to use metal-TA coatings to cover the formed zein/ CMCS NPs. The amino groups in CMCS could also form coordination bonds with metal ions, which are sensitive to external $\mathrm{pH}$ variations. ${ }^{34}$ As known, different structure of ligands and different electronic configuration of the metal ion would give rise to different structure and stability of the coordination complex by which the onset of responsive $\mathrm{pH}$ can be controlled and designed. ${ }^{6}$ The $-\mathrm{NH}_{2}$ groups in CMCS and $-\mathrm{OH}$ groups in TA have been chosen as ligands for the pH-responsive films. Zein/CMCS NPs provided space to load molecules and prevented them from chemical or biological attack by external substances before their intended release. Therefore, we designed a pH-responsive delivery system tailored by the formation and breakage of metal ion-ligand coordination bonds, which are responsive to $\mathrm{pH}$ changes.

\section{Materials and methods \\ Materials}

Zein (Z0001) was purchased from Tokyo Chemistry Industry, Co., Ltd. (Tokyo, Japan). CMCS was purchased from Nantongxingcheng Biological Product Inc. (Nantong, Jiangsu Province, China) with a deacetylation degree of $96 \%$. TA was purchased from Aladdin Chemistry Co., Ltd, Shanghai, People's Republic of China. Doxorubicin hydrochloride (DOX), copper chloride $\left(\mathrm{CuCl}_{2} \cdot 2 \mathrm{H}_{2} \mathrm{O}\right)$, calcium chloride $\left(\mathrm{CaCl}_{2} \cdot 2 \mathrm{H}_{2} \mathrm{O}\right)$ and 3-( $\mathrm{N}$-morpholino)-propanesulfonic acid
(MOPS) were obtained from Sinopharm Chemical Reagents Co., Ltd. (Shanghai, People's Republic of China). Phosphate buffer solution (PBS) and methylthiazolyldiphenyltetrazolium bromide (MTT) were purchased from Sigma-Aldrich (St Louis, MO, USA). Dulbecco's Modified Eagle's Medium (DMEM), fetal bovine serum (FBS), trypsin-ethylenediaminetetraacetic acid and penicillin-streptomycin mixtures were purchased from Gibco ${ }^{\circledR}$ BRL (Carlsbad, CA, USA). Other chemicals used were of analytical grade.

Human hepatocellular liver carcinoma cell lines (HepG2 cells) were purchased from the China Center for Type Culture Collection (Wuhan University, Wuhan, People's Republic of China).

\section{Preparation of metal-TA-coated zein/CMCS NPs}

Metal-TA-coated zein/CMCS NPs were prepared as follows: zein $(10 \mathrm{mg} / \mathrm{mL})$ was first dissolved in $75 \%$ (v/v) ethanol, and CMCS was dissolved in MOPS buffer $(10 \mathrm{mM}, \mathrm{pH}$ 7.4) with different concentrations as stock solution. Then, $0.5 \mathrm{~mL}$ of zein solution was rapidly added to $9.5 \mathrm{~mL}$ of CMCS solution with the weight ratio of 2:1, 1:1 or 1:2 (zein to $\mathrm{CMCS})$. Next, $100 \mu \mathrm{L}$ of TA solution $(24 \mathrm{mM})$ was added and briefly vortexed. Immediately following this, $100 \mu \mathrm{L}$ of fresh metal solution $\left(24 \mathrm{mM}, 48 \mathrm{mM}\right.$ or $72 \mathrm{mM}$ of $\mathrm{CuCl}_{2}$ or $\mathrm{CaCl}_{2}$ solutions) was added. The product was dialyzed (molecular weight cut-off [MWCO] 3,500 Da) against deionized water for $48 \mathrm{~h}$ and then freeze-dried for $48 \mathrm{~h}$ to obtain dry powders.

\section{Characterization of metal-TA-coated zein/CMCS NPs \\ Dynamic laser scattering (DLS) and zeta potential analysis}

Hydrodynamic diameters and zeta potential of the freshly prepared NPs were measured on a commercial laser light scattering instrument (Nano-ZS90; Malvern Instruments Ltd., Malvern, UK). All measurements were performed at $25^{\circ} \mathrm{C}$.

\section{Stability of metal-TA-coated NPs}

The effect of DMEM on the stability of NPs was monitored by diluting 10 -fold in DMEM and incubating at $37^{\circ} \mathrm{C}$ for $24 \mathrm{~h}$. The particle size and polydispersity index (PDI) were measured by DLS instrument as a function of time.

\section{Transmission electron microscope (TEM)}

Morphology of the NPs was acquired using TEM, JEM-2100F (JEOL, Tokyo, Japan). The slides were prepared by mounting sample solutions onto copper grids coated with carbon, followed by drying under ambient conditions. 
Fourier transform infrared spectroscopy (FTIR) and X-ray photoelectron spectroscopy (XPS) analyses FTIR spectra were acquired on a Jasco 4100 series (Jasco Inc., Easton, MO, USA). Lyophilized samples and potassium bromide $(\mathrm{KBr})$ were prepared as $\mathrm{KBr}$ pellets and scanned using blank $\mathrm{KBr}$ pellet as background. XPS analysis of all lyophilized samples was conducted on an axis ultra DLD apparatus (Kratos, Manchester, UK).

\section{Preparation of DOX-loaded NPs}

DOX was first dissolved in $75 \%$ ethanol, mixed with zein solution for $60 \mathrm{~min}$ with the concentration of $0.8 \mathrm{mg} / \mathrm{mL}$. The DOX-loaded formulation was prepared by adding the abovementioned solution into CMCS solution dissolved in MOPS buffer (10 mM, pH 7.4) with the weight ratio of 2:1, 1:1 or $1: 2$ (zein to CMCS). Then, $100 \mu \mathrm{L}$ of TA solution $(24 \mathrm{mM})$ was added dropwise. Immediately following this, $100 \mu \mathrm{L}$ of fresh metal solution $(24 \mathrm{mM}, 48 \mathrm{mM}$ or $72 \mathrm{mM}$ of $\mathrm{CuCl}_{2}$ or $\mathrm{CaCl}_{2}$ solutions) was added and dispersed. The final concentration of DOX was $40 \mu \mathrm{g} / \mathrm{mL}$. After centrifugation at $4,000 \times \mathrm{g}$ for $30 \mathrm{~min}$, DOX in the percolated solutions was measured with a UV/Visible (vis) spectrophotometer (UV-1100, Shanghai Mapada Instruments Co. Ltd., Shanghai, People's Republic of China) at $480 \mathrm{~nm}$. The encapsulation efficiency was defined as follows:

$$
\mathrm{EE}(\%)=\frac{\text { Total DOX }- \text { Free DOX }}{\text { Total DOX }} \times 100 \%
$$

\section{In vitro release study}

Drug release from NPs was carried out using a dialysis method under different $\mathrm{pH}$ conditions. Briefly, drug-loaded NPs were placed in a 3,500 Da MWCO dialysis bag, then immersed in $100 \mathrm{~mL} 0.01 \mathrm{M}$ release medium (pH 7.4, 6, 5 or 4) and put in $37^{\circ} \mathrm{C}$ baths and shaken at a speed of $100 \mathrm{rpm}$. At appropriate intervals, $1 \mathrm{~mL}$ of dissolution sample was taken out and replaced with fresh media. The concentration of DOX was measured with a UV/vis spectrophotometer (UV-1100, Shanghai Mapada Instruments Co. Ltd.).

\section{Cytotoxicity assay}

HepG2 cells were seeded in 96-well microplates at the density of $1 \times 10^{4}$ cells $/$ well in $100 \mu \mathrm{L}$ DMEM containing $10 \%$ FBS and $1 \%$ penicillin-streptomycin. The cells were incubated for $24 \mathrm{~h}$ in a humidified environment with $5 \% \mathrm{CO}_{2}$ at $37^{\circ} \mathrm{C}$ to allow cell attachment. Then, the medium was replaced by NPs containing medium (either blank or DOX containing NPs) with different doses of DOX ranging from $0.1 \mu \mathrm{g} \mathrm{mL}^{-1}$ to $4 \mu \mathrm{g} \mathrm{mL}^{-1}$ for further incubation of $24 \mathrm{~h}$. After removing the
NPs containing medium, $200 \mu \mathrm{L}$ of MTT solution $(0.5 \mathrm{mg} /$ $\mathrm{mL}$ ) was added to each well and incubated for another $4 \mathrm{~h}$. Then, the culture solution was removed carefully, and $100 \mu \mathrm{L}$ of dimethyl sulfoxide was added to each well to solubilize the formazan crystals. The absorbance of the solution was measured on a multilabel microplate reader (Victor X3 2030, PerkinElmer, Waltham, MA, USA) at $490 \mathrm{~nm}$. Cell viability (\%) was expressed by the following equation:

$$
\begin{aligned}
& \text { Cell viability (\%) } \\
& =\frac{\text { Absorbance } 490 \mathrm{~nm} \text { of treated group }}{\text { Absorbance } 490 \mathrm{~nm} \text { of control group }} \times 100 \%
\end{aligned}
$$

\section{Morphology observation}

The morphology of the cells after incubation for $24 \mathrm{~h}$ with blank or DOX-loaded NPs was evaluated by using optical microscopy with a $10 \times$ objective.

\section{Intracellular uptake study}

For quantitative study, HepG2 cells were plated on a six-well plate at a density of $2 \times 10^{5}$ cells/well with $2 \mathrm{~mL}$ growth medium. After incubation at $37^{\circ} \mathrm{C}$ for $24 \mathrm{~h}, 2 \mathrm{~mL}$ of DOX-loaded NPs containing medium was added and incubated for $1 \mathrm{~h}, 2 \mathrm{~h}, 4 \mathrm{~h}$ or $6 \mathrm{~h}$, respectively. After incubation, the culture medium was removed, and the cells were washed three times with cold PBS and harvested. The mean fluorescence intensity of DOX in cells was measured by flow cytometry analysis (Beckman Coulter, Miami, FL, USA).

For qualitative study, cells were seeded in a $35 \mathrm{~mm}$ Petri dish at a density of $1 \times 10^{5}$ cells/well with $2 \mathrm{~mL}$ growth medium and then cultured for $24 \mathrm{~h}$. Cells were washed three times after incubation for $1 \mathrm{~h}, 2 \mathrm{~h}, 4 \mathrm{~h}$ or $6 \mathrm{~h}$ using DOX-loaded NPs and then fixed by $4 \%$ paraformaldehyde in PBS ( $\mathrm{pH}$ 7.4) for $20 \mathrm{~min}$. The cells were further washed twice with PBS. Fluorescence images of the cells were observed by confocal laser scanning microscopy (CLSM; Zeiss LSM 710, Carl Zeiss AG, Oberkochen, Germany).

\section{Statistics analysis}

Statistical analysis was performed by SPSS 18.0 using analysis of variance (ANOVA) and Student's $t$-test to compare the significant difference. $P<0.05$ was considered to be statistically significant.

\section{Results and discussion Preparation and stability of metal- TA-coated zein/CMCS NPs}

It has been reported that complexation between TA and metal ions could form robust nanoscale films on various 
templates. ${ }^{35-37}$ The formation and cleavage of coordination bonds between TA and metal ions are $\mathrm{pH}$ dependent. ${ }^{38}$ Herein, we engineered a kind of drug delivery system based on metal-TA films on zein/CMCS NPs, and the coated NPs exhibited controllable pH-dependent intracellular drug release (Scheme 1). In addition, the amino groups in CMCS could also form coordination bonding with metal ions, which improved the stimulus sensitivity of this system, especially in mild acidic conditions, compared with our previous work.

Particle size and zeta potential in different formulations are shown in Tables $\mathrm{S} 1-\mathrm{S} 3$. When $\mathrm{Cu}^{2+}$ was chosen as the coordinating center, the particle size of zein/CMCS NPs increased after being coated by $\mathrm{Cu}^{2+}$-TA films at each zein to $\mathrm{CMCS}$ ratio. Additionally, at each zein to $\mathrm{CMCS}$ ratio, an increasing trend with the increase in the amount of metal ions added was witnessed. At a zein to CMCS ratio of 1:1, the particle size of $\mathrm{Zein}_{1} / \mathrm{CMCS}_{1}-\mathrm{TA} / \mathrm{Cu}_{1}{ }^{2+} \mathrm{NPs}$ was only $96.6 \mathrm{~nm}$, which might be because $-\mathrm{NH}_{2},-\mathrm{OH}$ and metal ions were tightly connected through the robust coordination bonding. When using $\mathrm{Ca}^{2+}$ as a cross-linker, the smallest particle size was obtained at a zein to CMCS ratio of 1:2. The PDI for all formulations was $<0.3$, which indicated narrow distribution of particle size. The zeta potential of zein/CMCS NPs was $\sim-25 \mathrm{mV}$, but shifted to lower value after being coated by TA-metal films because of the acidic nature of galloyl groups in TA. ${ }^{30}$

In order to evaluate the cellular behavior, the NPs should be stable during incubation at $37^{\circ} \mathrm{C}$ in culture media. Therefore, we measured the particle size and PDI of NPs when incubated in DMEM. As shown in Figure 1, all formulations in DMEM witnessed an increase in particle size. For zein $_{1} / \mathrm{CMCS}_{1}$ NPs, the particle size increased to $\sim 340 \mathrm{~nm}$

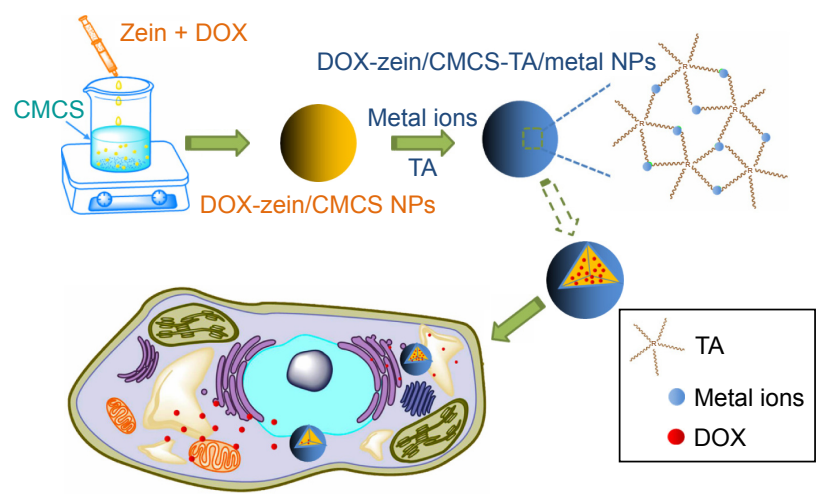

Scheme I Illustration of the synthesis and structures of DOX-loaded zein/CMCS NPs coated by metal-TA films and the proposed model for $\mathrm{pH}$-dependent drug release in tumor cells.

Abbreviations: CMCS, carboxymethyl chitosan; DOX, doxorubicin hydrochloride; NPs, nanoparticles; TA, tannic acid. during the first hour and dropped down to $\sim 300 \mathrm{~nm}$ in the following hours. For the coated NPs, only a slight increase by $20-40 \mathrm{~nm}$ was observed. The increase in particle size of zein $1 \mathrm{CMCS}_{1}$ NPs was due to the high glucose content in culture media, which may interact with protein and polysaccharide to form larger aggregation. In addition, the stronger ionic strength in the media was also partly attributed to the large particle size, ${ }^{39}$ while the coated NPs could avoid such effect.

\section{Characterization of metal-TA-coated zein/CMCS NPs}

As shown in the TEM images, for zein ${ }_{1} / \mathrm{CMCS}_{1}$ NPs without coatings (Figure 2A), the particles tend to clump and connect to each other and it was hard to see individual ones which also preformed in previous studies. ${ }^{32,33}$ However, metal-TAcoated NPs shared features of a spherical shape and more homogeneous distribution compared with zein $/ \mathrm{CMCS}_{1}$ NPs (Figure $2 \mathrm{C}$ and $\mathrm{E}$ ). The particle size distribution kept the monomodel structure in all formulations (Figure 2B, D and F). When the amount of metal ions was increased, the particle size further increased, while the morphology changes of NPs were not observed (Figure $2 \mathrm{G}$ and $\mathrm{H}$ ). In Figure 2E, the color of the NPs suspension changed after being coated with $\mathrm{Cu}^{2+}-\mathrm{TA}$ film. Additionally, the suspension was a deep color at higher $\mathrm{Cu}^{2+}$ concentration. This color change is consistent with observations in previous work. ${ }^{30}$

The intermolecular interaction between different components was characterized by FTIR (Figure S1). The O-H stretching band of the hydroxyl groups of TA was at $3,396 \mathrm{~cm}^{-1}$. In the spectra of CMCS, a broad, unstructured absorption close to $3,436 \mathrm{~cm}^{-1}$ was relevant to superposition of $-\mathrm{OH}$ and $-\mathrm{NH}_{2}$ groups. In the spectra of metal-TAcoated NPs, this peak shifted to $3,295 \mathrm{~cm}^{-1}$, suggesting that the coordination bonding was formed between $-\mathrm{OH}$ or $-\mathrm{NH}_{2}$ and copper. ${ }^{34} \mathrm{CMCS}$ showed a characteristic peak at $1,605 \mathrm{~cm}^{-1}$, corresponding to the stretching vibrations of $\mathrm{C}=\mathrm{O},{ }^{40}$ which could also be seen in the spectra of metalTA-coated NPs. The peaks at $1,322 \mathrm{~cm}^{-1}$ and $1,205 \mathrm{~cm}^{-1}$ in the spectrum of TA could be assigned to the deformation of phenolic groups. ${ }^{41,42}$ In the spectrum of metal-TA-coated NPs, the peaks of phenolic deformation were more broadened than the TA peaks. With the increase in $\mathrm{Cu}^{2+}$ amount, the peak at $1,322 \mathrm{~cm}^{-1}$ shifted to $1,343 \mathrm{~cm}^{-1}$ gradually. These changes were attributed to the complexation of the TA and metal ions. As shown in the FTIR spectrum of metal-TA-coated NPs, the peaks at $1,205 \mathrm{~cm}^{-1}$ in the spectra of TA shift to $1,201 \mathrm{~cm}^{-1}$ in NPs-TA/ $\mathrm{Cu}_{1}{ }^{2+}, \mathrm{NPs}-\mathrm{TA} / \mathrm{Cu}_{2}{ }^{2+}$, 

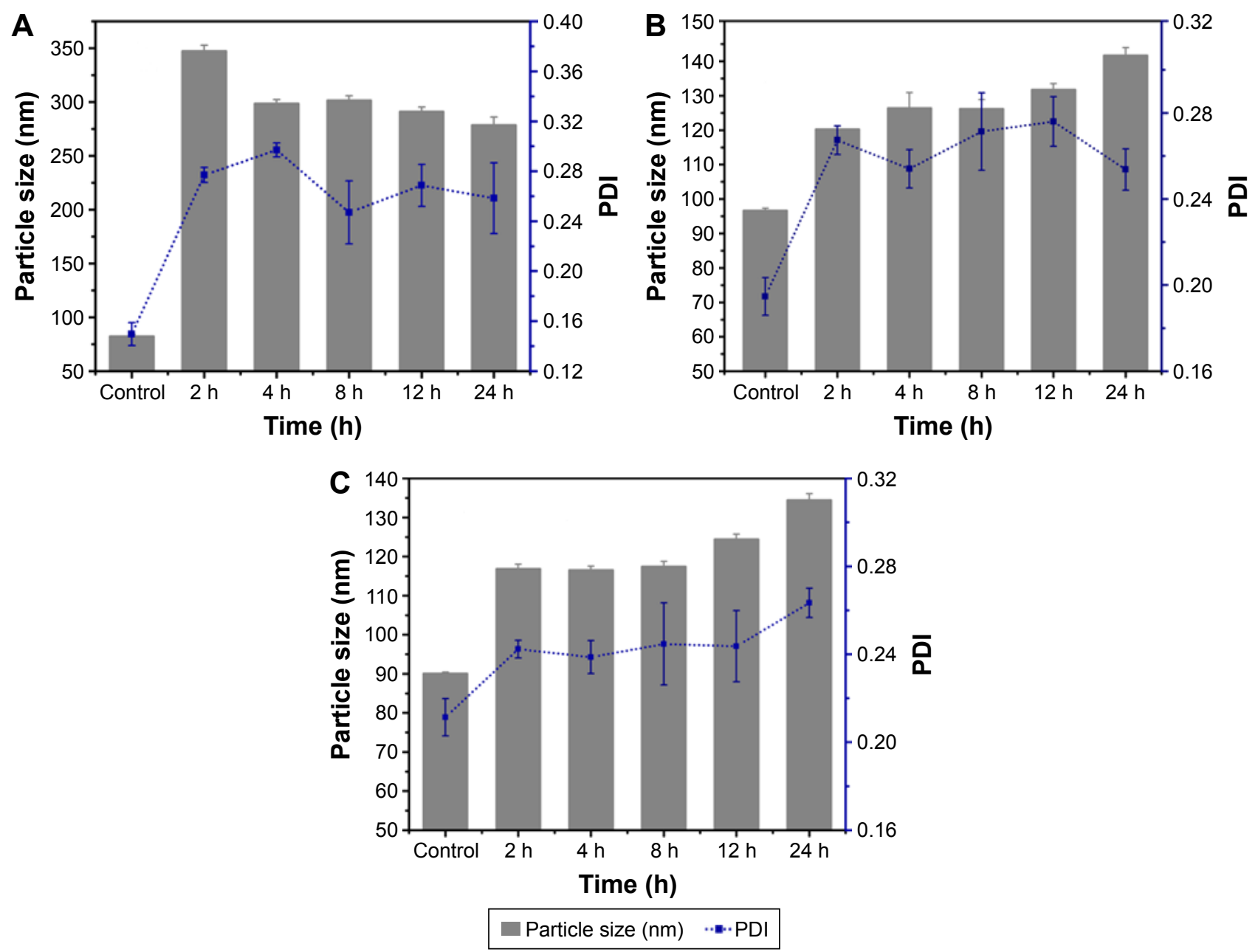

Figure I Particle size and PDI in culture media as a function of time: $\mathrm{Z}_{1} / \mathrm{CMCS}_{1} \mathrm{NPs}(\mathbf{A}), \mathrm{Z}_{1} / \mathrm{CMCS}_{1}-\mathrm{TA} / \mathrm{Cu}_{1}{ }^{2+} \mathrm{NPs}(\mathbf{B})$ and $\mathrm{Z}_{1} / \mathrm{CMCS}_{1}-\mathrm{TA} / \mathrm{Ca}^{2+} \mathrm{NPs}(\mathbf{C})$.

Notes: Control referred to the freshly prepared NPs without I0-fold diluting in culture media. Data displayed as mean \pm SD ( $n=3$ ). The $Z_{1} / C M C S, N P s$ were prepared at a zein:CMCS ratio of $\mathrm{I}: \mathrm{I} \mathrm{w} / \mathrm{w}$ with the final metal ion concentration of $0.24 \mathrm{mM}\left(\mathrm{Cu}_{1}{ }^{2+}\right.$ or $\left.\mathrm{Ca}^{2+}\right)$.

Abbreviations: CMCS, carboxymethyl chitosan; NPs, nanoparticles; PDI, polydispersity index; TA, tannic acid; SD, standard deviation; $Z_{\text {, }}$ zein .

NPs-TA/ $\mathrm{Ca}^{2+}$ and $1,199 \mathrm{~cm}^{-1}$ in NPs-TA/ $/ \mathrm{Cu}_{3}^{2+}$, confirming once again the coordination bonds between phenolic groups of TA and metal ions. XPS analysis was performed to further confirm the surface chemical information of the NPs (Figure S2 and Table S4). Figure S2A and B display the survey scan spectrum of NPs-TA/ $\mathrm{Cu}^{2+}$ and NPs-TA/ $\mathrm{Ca}^{2+}$. $\mathrm{Cu} 2 \mathrm{p}$ signal and $\mathrm{Ca} 2 \mathrm{p}$ signal were observed in the survey scan spectra of NPs-TA/Cu ${ }^{2+}$ (Figure S2A) and NPs-TA/ $\mathrm{Ca}^{2+}$ (Figure S2B), respectively. Hence, the XPS survey scan spectra could confirm the presence of metal on the surface of coated NPs.

\section{Preparation and characterization of DOX-loaded NPs}

The complex NPs prepared with the combination of zein and CMCS have been developed as versatile delivery systems for various bioactives. ${ }^{33}$ A previous study confirmed that DOX could be loaded in zein NPs. ${ }^{7}$ Furthermore, the positively charged DOX could be absorbed onto the surface of negatively charged zein/CMCS NPs by electrostatic interaction. ${ }^{7,22,43,44}$ The particle size of DOX-loaded zein $/$ / $\mathrm{CMCS}_{1}$ NPs was $135.2 \mathrm{~nm}$ with ideal PDI, and the encapsulation efficiency was $91.0 \%$ (Table S5). After being coated by $\mathrm{Cu}_{1}{ }^{2+}$-TA films or $\mathrm{Ca}^{2+}-\mathrm{TA}$ films, a slight increase in particle size was witnessed, reaching $140.6 \mathrm{~nm}$ and $137.6 \mathrm{~nm}$, respectively, with relatively small PDI, and the EE\% was improved to $96.1 \%$ and $93.4 \%$ at a metal ion concentration of $0.24 \mathrm{mM}$ (Table S5). When the concentration of $\mathrm{Cu}^{2+}$ was increased, the particle size increased. At a zein/CMCS ratio of 1:1 or 1:2, the particle size decreased in all formulations (Tables S5 and S6) compared with the size at a zein/CMCS ratio of 2:1 (Table S7). In Figure 3, TEM micrograph displayed that the incorporation of DOX in metal-TA-coated NPs showed clear spherical shape and homogeneous distribution. 


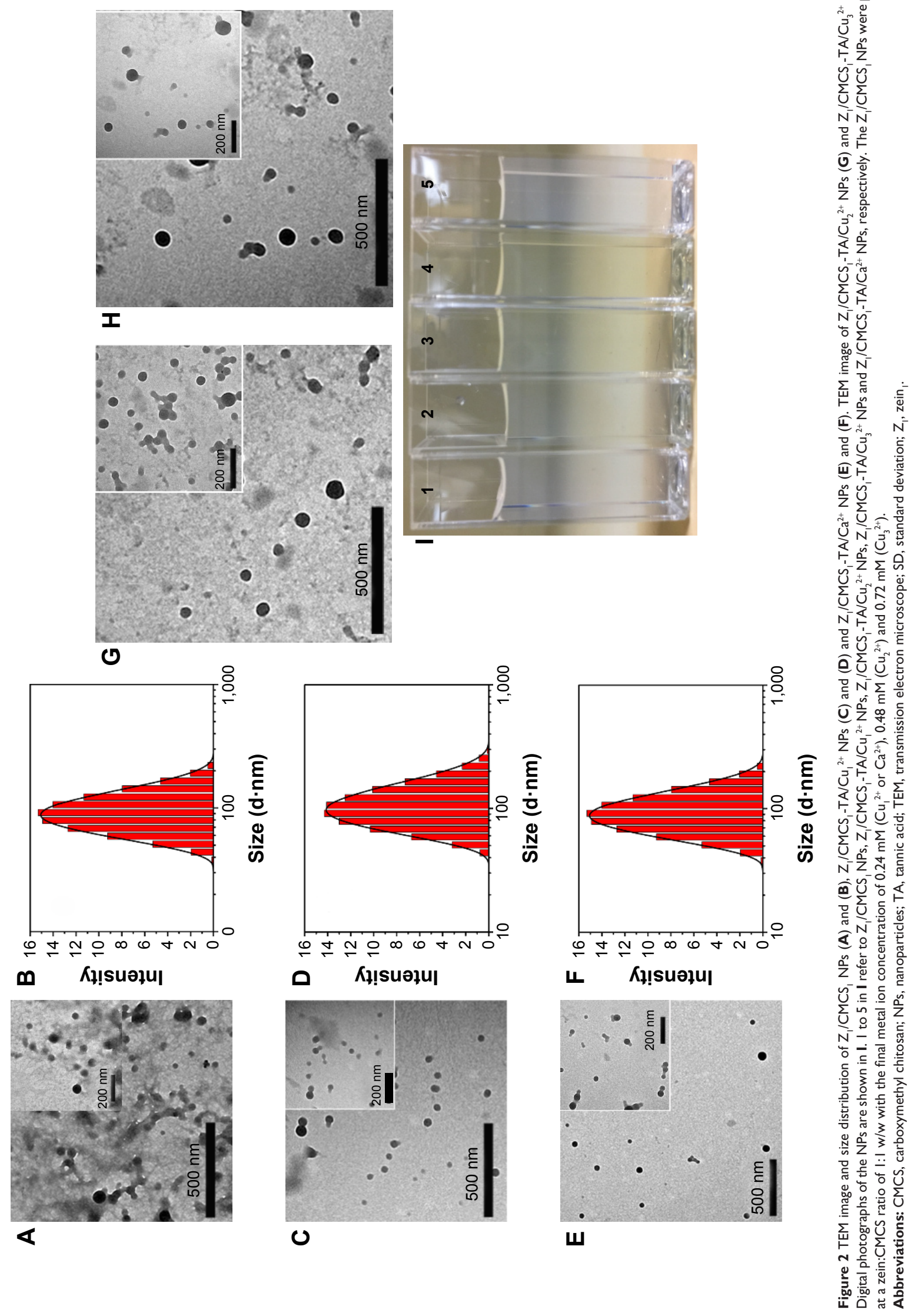



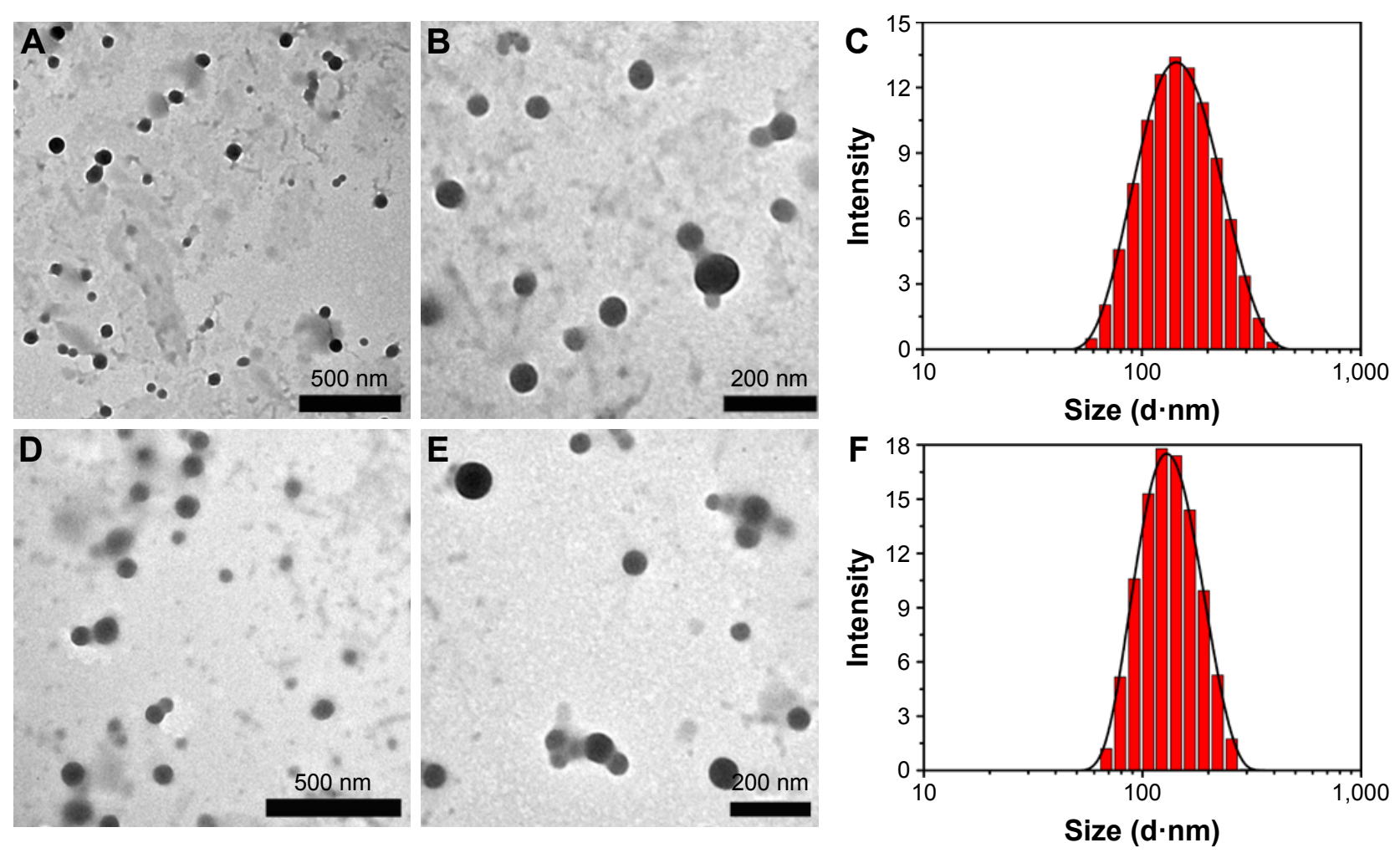

Figure 3 TEM image and size distribution of DOX-loaded $Z_{1} / C M C S_{1}-T A / C u_{1}{ }^{2+} N P s(A-C)$ and $Z_{1} / C M C S_{1}-T A / C a^{2+}(\mathbf{D}-F)$. The Z /CMCS, NPs were prepared at zein:CMCS ratio of I:I w/w with the final metal ion concentration of $0.24 \mathrm{mM}\left(\mathrm{Cu}_{1}{ }^{2+}\right.$ or $\left.\mathrm{Ca}^{2+}\right)$.

Abbreviations: CMCS, carboxymethyl chitosan; DOX, doxorubicin hydrochloride; NPs, nanoparticles; TA, tannic acid; TEM, transmission electron microscope; $Z_{1}$, zein .

\section{In vitro drug release}

In order to examine the in vitro release behavior of DOXloaded NPs, we chose the release medium at $\mathrm{pH} 7.4,6,5$ and 4 to simulate normal physiological conditions, the tumor site, endosomal and lysosomal compartments, respectively. ${ }^{15,45-47}$ Figures 4 and 5 show the cumulative amount of DOX released from DOX-loaded NPs. As shown in Figure $4 \mathrm{~A}, \sim 70 \%$ of DOX was released at $\mathrm{pH} 7.4$ from zein $_{1} / \mathrm{CMCS}_{1}$ NPs into bulk solution within $8 \mathrm{~h}$, while the cumulative release of DOX was $\sim 90 \%$ at $\mathrm{pH} 4$ during the same time period. It can be seen that zein/CMCS NPs also showed $\mathrm{pH}$-responsive release of DOX due to the weak hydrophobic interactions and electrostatic repulsions between the NPs and DOX in acidic environment. ${ }^{22,48}$ The pH-responsive release of DOX via $\mathrm{Cu}^{2+}-\mathrm{TA}$ or $\mathrm{NH}_{2}-\mathrm{Cu}^{2+}$ coordination bonding using zein/CMCS NPs as a carrier demonstrated the responsiveness of the system to $\mathrm{pH}$ variations and its designability (Figure 4B-G). At a zein/CMCS ratio of 2:1, under the physiological condition $(\mathrm{pH} 7.4)$ and mildly acidic condition ( $\mathrm{pH} 6$ ), the release was slow, and
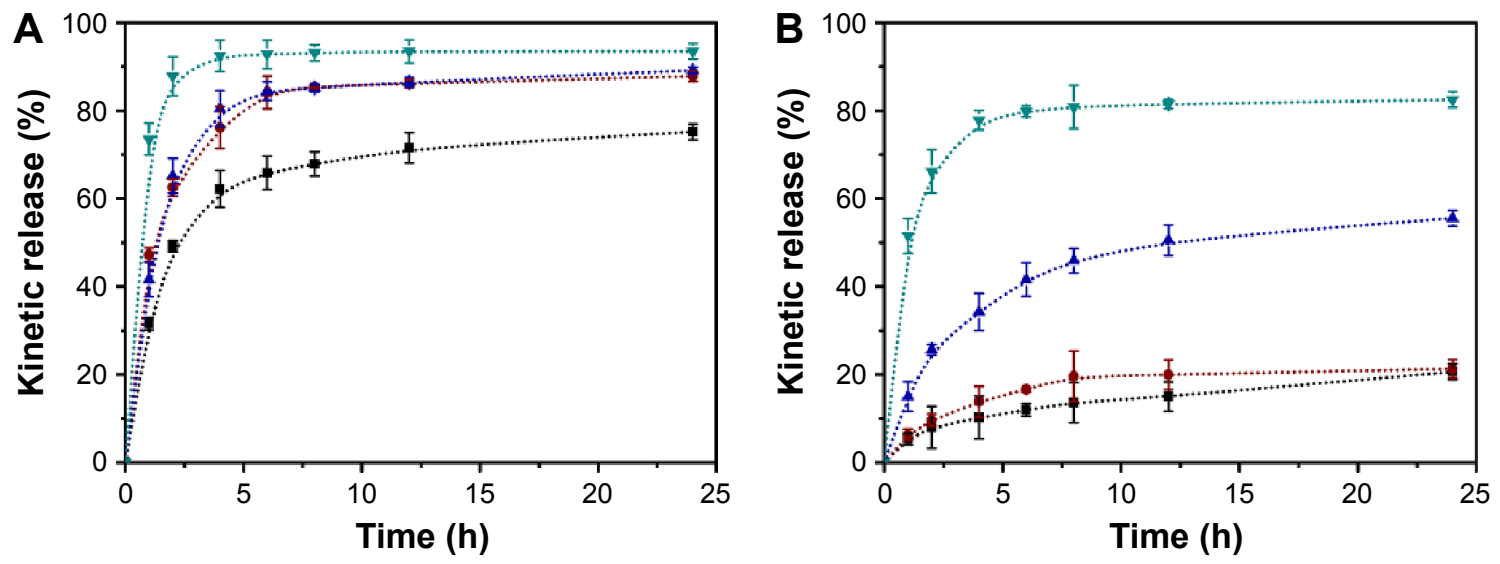

Figure 4 (Continued) 

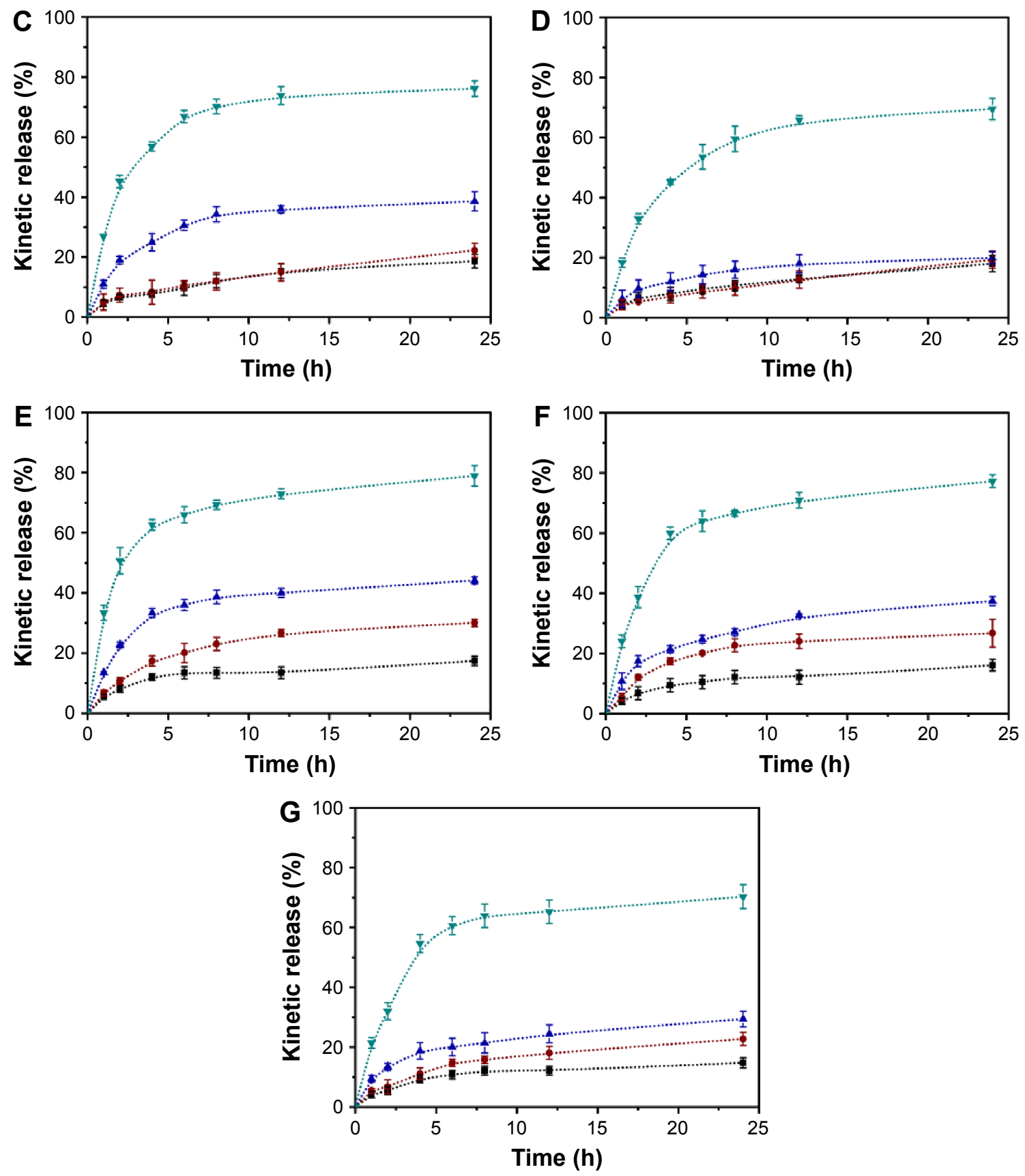

$\ldots+\cdots \mathrm{pH} 7.4 \ldots \ldots \mathrm{pH} 6 \ldots \mathrm{pH} 5 \ldots \ldots \mathrm{pH} 4$

Figure 4 In vitro release profiles of DOX-loaded $Z_{1} / C M C S_{1} N P s(\mathbf{A}), Z_{2} / C M C S_{1}-T A / C u_{1}{ }^{2+} N P s(B), Z_{2} / C M C S_{1}-T A / C u_{2}{ }^{2+} N P s(C), Z_{2} / C M C S_{1}-T A / C u_{3}{ }^{2+} N P s(D), Z_{1} / C M C S_{1}-$ $\mathrm{TA} / \mathrm{Cu}_{1}{ }^{2+} \mathrm{NPs}(\mathbf{E}), \mathrm{Z}_{1} / \mathrm{CMCS}_{1}-\mathrm{TA} / \mathrm{Cu}_{2}{ }^{2+} \mathrm{NPs}(\mathbf{F})$ and $\mathrm{Z}_{1} / \mathrm{CMCS}_{1}-\mathrm{TA} / \mathrm{Cu}_{3}{ }^{2+} \mathrm{NPs}(\mathbf{G})$ in $0.01 \mathrm{M}$ buffer under different $\mathrm{pH}$ conditions.

Notes: The $\mathrm{Z}_{2} / \mathrm{CMCS}_{1}-\mathrm{TA} / \mathrm{metal} \mathrm{NPs}$ were prepared at a zein:CMCS ratio of $2: 1 \mathrm{w} / \mathrm{w}$ with the final metal ion concentration of $0.24 \mathrm{mM}\left(\mathrm{Cu}_{1}{ }^{2+}\right.$ or $\left.\mathrm{Ca}^{2+}\right), 0.48 \mathrm{mM}\left(\mathrm{Cu}_{2}{ }^{2+}\right)$ and $0.72 \mathrm{mM}\left(\mathrm{Cu}_{3}{ }^{2+}\right)$. The $\mathrm{Z}_{1} / \mathrm{CMCS}_{1}-\mathrm{TA} /$ metal NPs were prepared at a zein:CMCS ratio of I:I w/w with the final metal ion concentration of $0.24 \mathrm{mM}\left(\mathrm{Cu}_{1}{ }^{2+}\right.$ or $\left.\mathrm{Ca}^{2+}\right), 0.48 \mathrm{mM}$ $\left(\mathrm{Cu}_{2}^{2+}\right)$ and $0.72 \mathrm{mM}\left(\mathrm{Cu}_{3}{ }^{2+}\right)$.

Abbreviations: CMCS, carboxymethyl chitosan; DOX, doxorubicin hydrochloride; NPs, nanoparticles; TA, tannic acid; $Z_{1}$, zein $;$; $Z_{2}$, zein ${ }_{2}$.

only $\sim 18 \%$ and $20 \%$ of DOX were detected at $\mathrm{pH} 7.4$ and 6 within $12 \mathrm{~h}$, respectively (Figure 4B). In contrast, release rate was readily accelerated in acidic conditions, and $\sim 50 \%$ and $80 \%$ of DOX were released within $8 \mathrm{~h}$ at $\mathrm{pH} 5$ and $\mathrm{pH}$ 4 , respectively. The lower the $\mathrm{pH}$ the NPs encountered, the faster the drug was released, due to the weak affinity of the
$\mathrm{Cu}^{2+}$ ions to both TA and CMCS under low $\mathrm{pH}$ conditions. The metal-ligand films had controllable $\mathrm{pH}$-dependent degradability, which led to an association of DOX release profile with the film degradation kinetics. ${ }^{35-37,49}$ When the amount of $\mathrm{Cu}^{2+}$ was increased, the onset of responsive $\mathrm{pH}$ dramatically reduced due to the high stability of the 
A

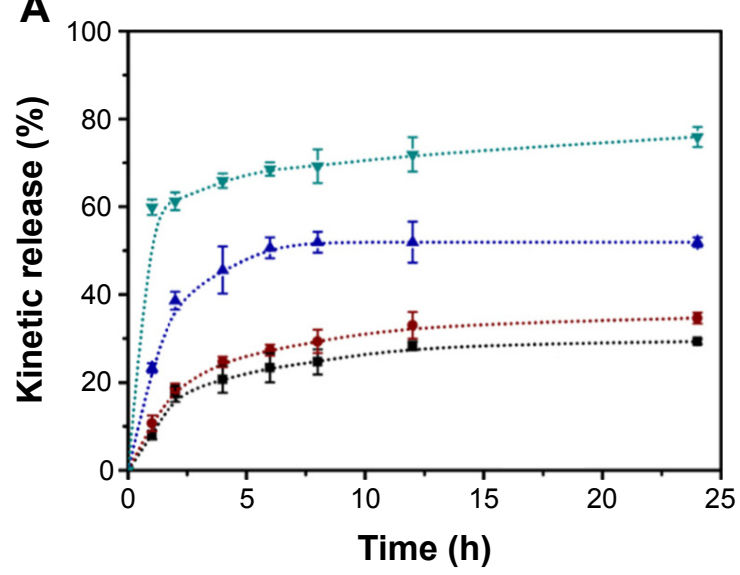

C

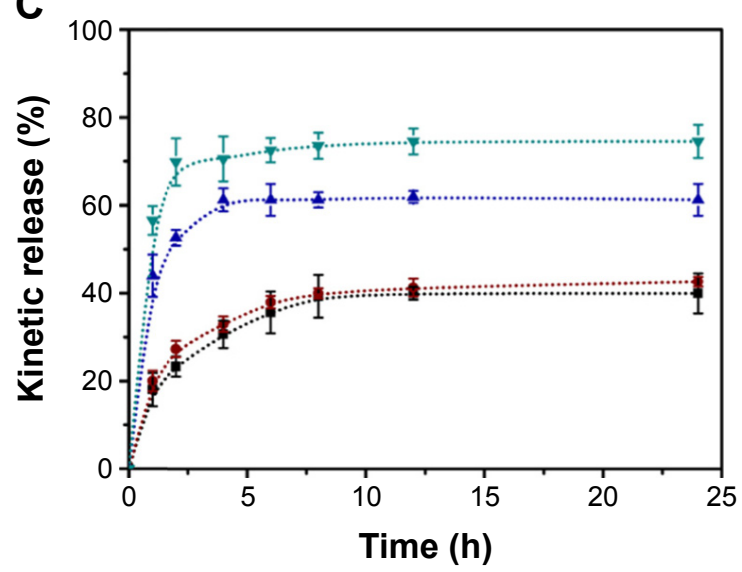

B

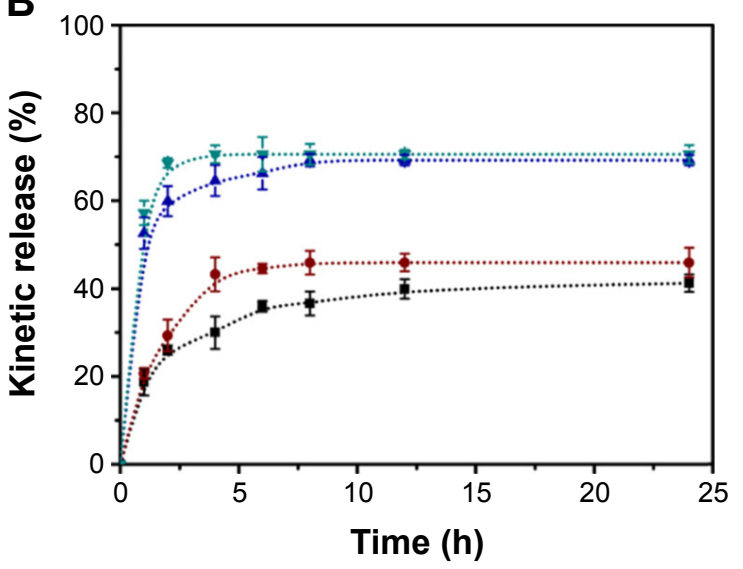

D

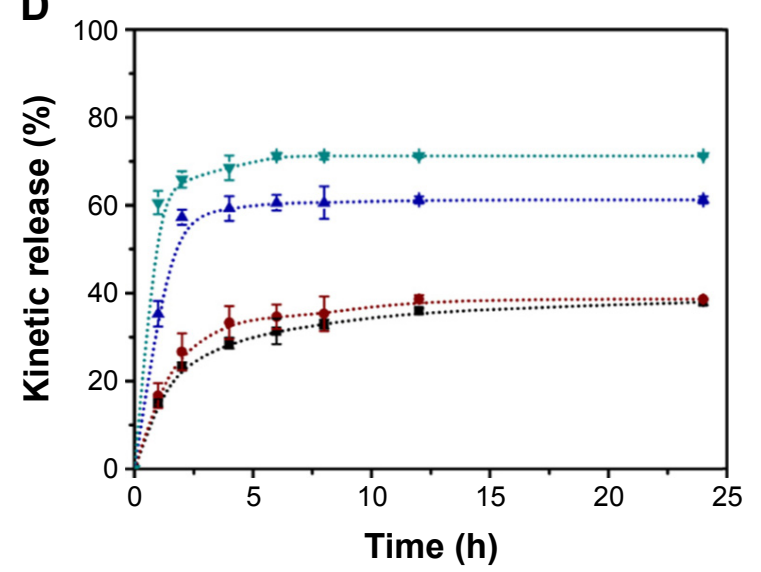

$\cdots \mathrm{pH} 7.4 \quad \cdots \bullet \cdots \mathrm{pH} 6 \quad \ldots \ldots \cdots \mathrm{pH} 5 \quad \cdots \cdots \cdots \mathrm{pH} 4$

Figure 5 In vitro release profiles of DOX-loaded $Z_{1} / \mathrm{CMCS}_{2}-\mathrm{TA} / \mathrm{Cu}_{1}{ }^{2+} \mathrm{NPs}(\mathbf{A}), \mathrm{Z}_{2} / \mathrm{CMCS}_{1}-\mathrm{TA} / \mathrm{Ca}^{2+} \mathrm{NPs}(\mathbf{B}), \mathrm{Z}_{1} / \mathrm{CMCS}_{1}-\mathrm{TA} / \mathrm{Ca}^{2+}(\mathbf{C})$ and $\mathrm{Z}_{1} / \mathrm{CMCS}_{2}-\mathrm{TA} / \mathrm{Ca}^{2+}(\mathbf{D})$ in $0.0 \mathrm{I} \mathrm{M}$ buffer under different $\mathrm{pH}$ conditions.

Abbreviations: CMCS, carboxymethyl chitosan; DOX, doxorubicin hydrochloride; NPs, nanoparticles; TA, tannic acid; $Z_{1}$, zein ${ }_{1} ; Z_{2}$, zein ${ }_{2}$.

$\mathrm{Cu}^{2+}-\mathrm{TA}$ or $\mathrm{NH}_{2}-\mathrm{Cu}^{2+}$ coordination bonding architecture (Figure 4C and D).

At a zein/CMCS ratio of $1: 1$, release percentages were $\sim 17 \%$ at $\mathrm{pH} 7.4$ and $\sim 30 \%$ at $\mathrm{pH} 6$ (Figure $4 \mathrm{E}$ ). Significant release of DOX has been observed when the $\mathrm{pH}$ of the medium was decreased (pH 5 and 4). In this system, the release of DOX increased at $\mathrm{pH} 6$ compared with zein/ CMCS at the ratio of 2:1, indicating the high sensitivity of the drug delivery system to $\mathrm{pH}$ stimulus.

From Figure 5A, one can see that TA release became faster with increasing CMCS concentration (at a zein/ CMCS ratio of 1:2). In this case, more metal ions interacted with $-\mathrm{NH}_{2}$ in CMCS instead of the $-\mathrm{OH}$ in TA, and the metal-ligand films were thin, leading to weak coordination bonding between metal and TA. When $\mathrm{Ca}^{2+}$ was chosen as the coordinating center, the release percentages were $\sim 40 \%$ and $45 \%$ at $\mathrm{pH} 7.4$ and $\mathrm{pH} 6$, respectively, at a zein/CMCS ratio of 2:1 (Figure 5B). Increase in CMCS concentration slightly decreased the release rate of DOX. This release behavior of
zein/CMCS-TA/ $\mathrm{Ca}^{2+}$ was attributed to the relatively weaker coordination of TA and $\mathrm{Ca}^{2+}$ than that of $\mathrm{Cu}^{2+}$, which resulted in the fast release of DOX.

The pH-dependent disassembly of metal-TA films on zein/CMCS NPs corresponded to a desirable profile for drug delivery as the NPs slowly release the drug in normal physiological environment, gradually release the loading under weak acidic conditions and quickly release the drug at $\mathrm{pH} 5$ or $\mathrm{pH} 4$, which correspond to those in endosomal and lysosomal compartments. In comparison to metal-TA-coated zein NPs in our previous work, the incorporation of CMCS significantly affected the coordination environment of TA and metal ions, which led to a higher $\mathrm{pH}$-sensitiveness to the stimuli.

\section{In vitro cytotoxicity study}

The in vitro cytotoxicity of blank NPs and DOX-loaded NPs against HepG2 cells was tested (Figure 6). It was apparent that blank NPs without DOX did not show significant cytotoxicity (Figure 6A). For all the DOX-loaded formulations, 

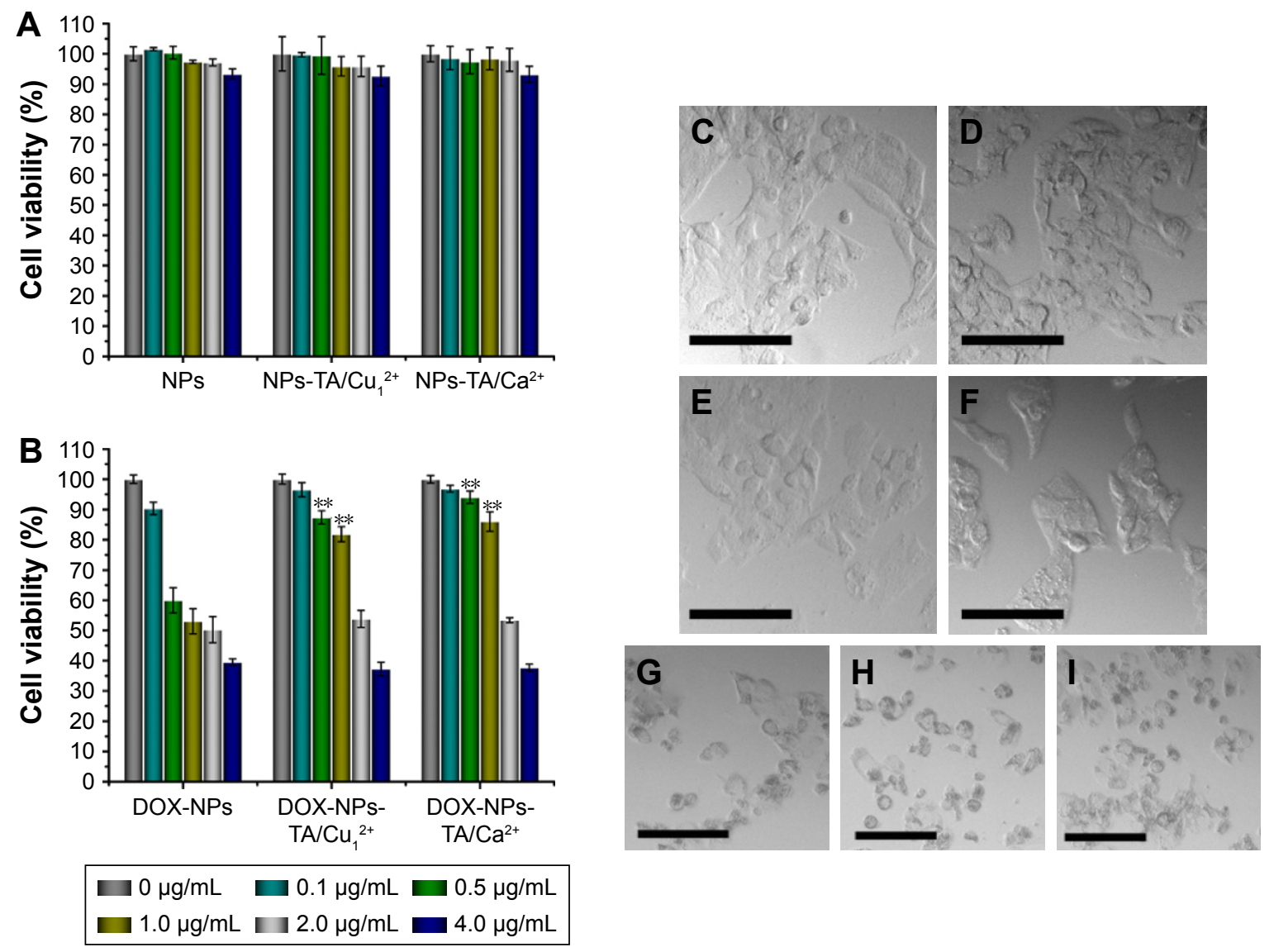

Figure 6 In vitro cytotoxicity of the blank NPs (A) and DOX-loaded NPs (B) against HepG2 cells incubated for 24 h.

Notes: In all panels, the indicated concentrations are DOX doses. It should be noted that for evaluating DOX-loaded NPs, equal concentrations of blank NPs were employed to eliminate the effect of vehicles in MTT assay. Data displayed as mean $\pm S D(n=6)$. ${ }^{*} P<0.0$ I versus DOX-NPs group. The morphology of the cells after incubating for $24 \mathrm{~h}$ with NPs $(\mathbf{D}), \mathrm{NPs}-\mathrm{TA} / \mathrm{Cu}_{1}{ }^{2+}(\mathbf{E})$ and NPs-TA/Ca ${ }^{2+}(\mathbf{F})$ or DOX-NPs $(\mathbf{G})$, DOX-NPs-TA/Cu ${ }_{1}{ }^{2+}(\mathbf{H})$ and DOX-NPs-TA/Ca ${ }^{2+}(\mathbf{I})$ was evaluated by using optical microscopy with a I0X objective. (C) was the control. The scale bars represent $100 \mu \mathrm{m}$.

Abbreviations: DOX, doxorubicin hydrochloride; MTT, methylthiazolyldiphenyltetrazolium bromide; NPs, nanoparticles; TA, tannic acid; SD, standard deviation.

the inhibition activity enhanced with increase in drug concentration (Figure 6B). Notably, after $24 \mathrm{~h}$ incubation at DOX concentrations ranging from $2 \mu \mathrm{g} / \mathrm{mL}$ to $0.1 \mu \mathrm{g} / \mathrm{mL}$, the cytotoxicity of the DOX-loaded metal-TA-coated NPs was lower than DOX-loaded zein/CMCS NPs against HepG2 cells (Figure 6B). As shown in Figure 4, DOX was released faster in zein/CMCS NPs compared with the coated NPs at $\mathrm{pH} 7.4$ or 6 , which led more free DOX to enter into the cells. Free DOX can be quickly transported into the cells by passive diffusion through the plasma membrane and can enter the active site, ${ }^{50,51}$ while the drug-loaded metal-TA-coated NPs traversed the plasma membrane through endocytosis, which was much slower than passive diffusion. ${ }^{52,53}$ The half maximal inhibitory concentration $\left(\mathrm{IC}_{50}\right)$ was also used to evaluate the antitumor activities. For HepG2 cells, the $\mathrm{IC}_{50}$ of DOX-NPs was $2.36 \pm 0.18 \mu \mathrm{g} / \mathrm{mL}$, while those for DOX-NPs-TA/ $\mathrm{Cu}_{1}{ }^{2+}$ and DOX-NPs-TA/ $\mathrm{Ca}^{2+}$ were $2.91 \pm 0.12 \mu \mathrm{g} / \mathrm{mL}$ and $2.67 \pm 0.28 \mu \mathrm{g} / \mathrm{mL}$, respectively (Table $\mathrm{S} 8$ ).
Figure 6C-I shows the microscopic examination of HepG2 cells after treatment with blank or DOX-loaded NPs for $24 \mathrm{~h}$. Cells treated with blank NPs (Figure 6D-F) did not have a changed morphology image compared with the control one (Figure 6C). For the treatment with DOX-loaded NPs, the cells became round, lost their characteristic stretched appearance, showed clear cytoplasmic blebbing and vacuolation (Figure 6G-I). ${ }^{54}$

\section{Intracellular uptake of NPs}

The cellular uptake of DOX-loaded NPs was evaluated on HepG2 cells at different time intervals using CLSM and flow cytometry (Figure 7). As shown in Figure 7A, after only $2 \mathrm{~h}$ of incubation, the red fluorescence appeared in the cytoplasm for DOX-loaded zein/CMCS NPs, indicating fast internalization of DOX inside the cells. The intensity of red fluorescence increased when extending the incubation time. Previous reports have shown that DOX fluorescence is observed only when DOX is released due to the self-quenching 
A
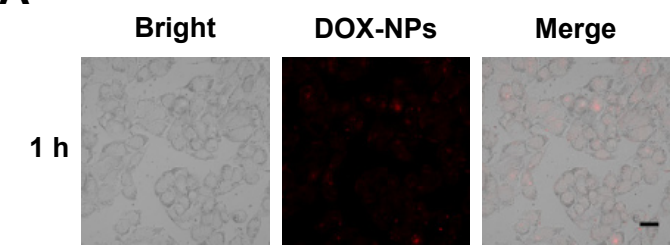

$2 \mathrm{~h}$

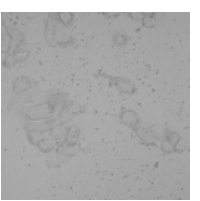

$4 \mathrm{~h}$

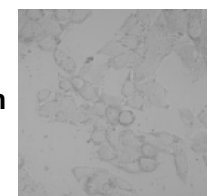

$6 \mathrm{~h}$

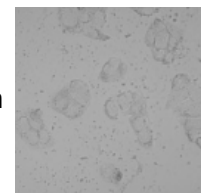

C

$1 \mathrm{~h}$
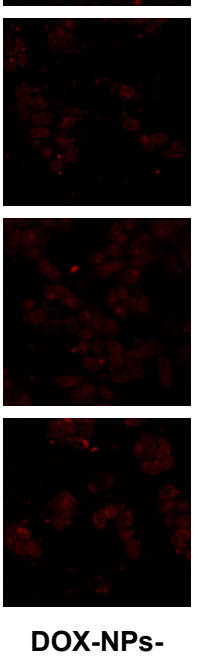
$\mathrm{TA} / \mathrm{Ca}^{2+}$

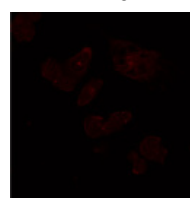

$2 \mathrm{~h}$
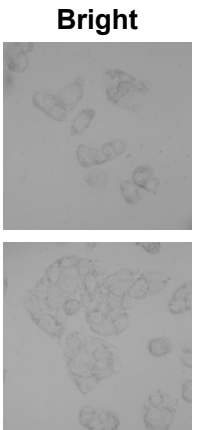

$4 \mathrm{~h}$

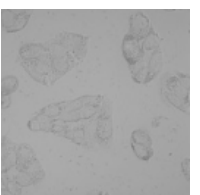

$6 \mathrm{~h}$

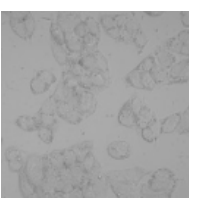

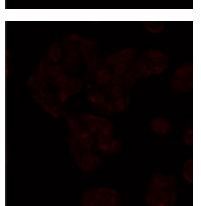
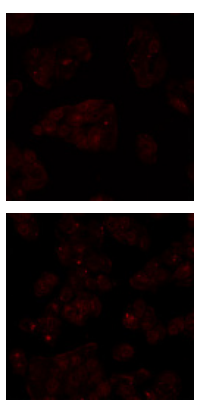
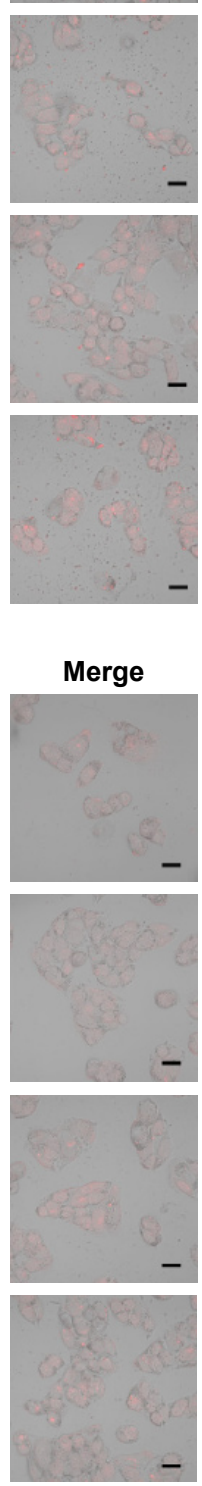

B

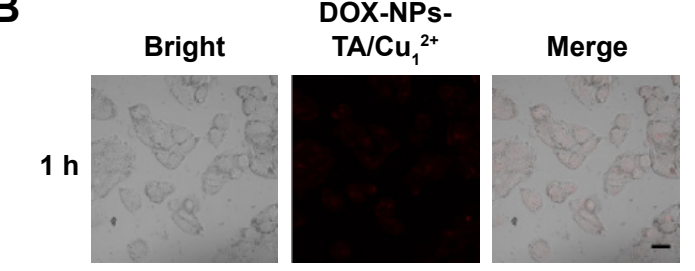

$2 \mathrm{~h}$
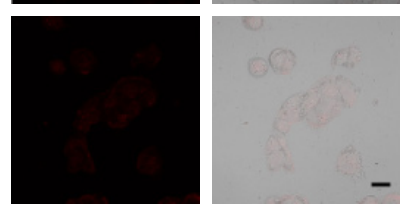

$4 \mathrm{~h}$
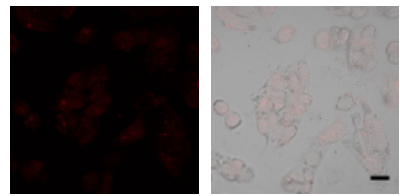

$6 \mathrm{~h}$
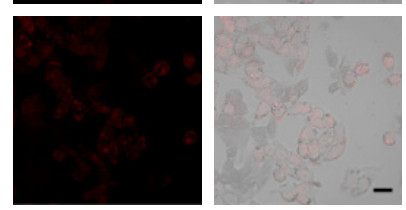

D

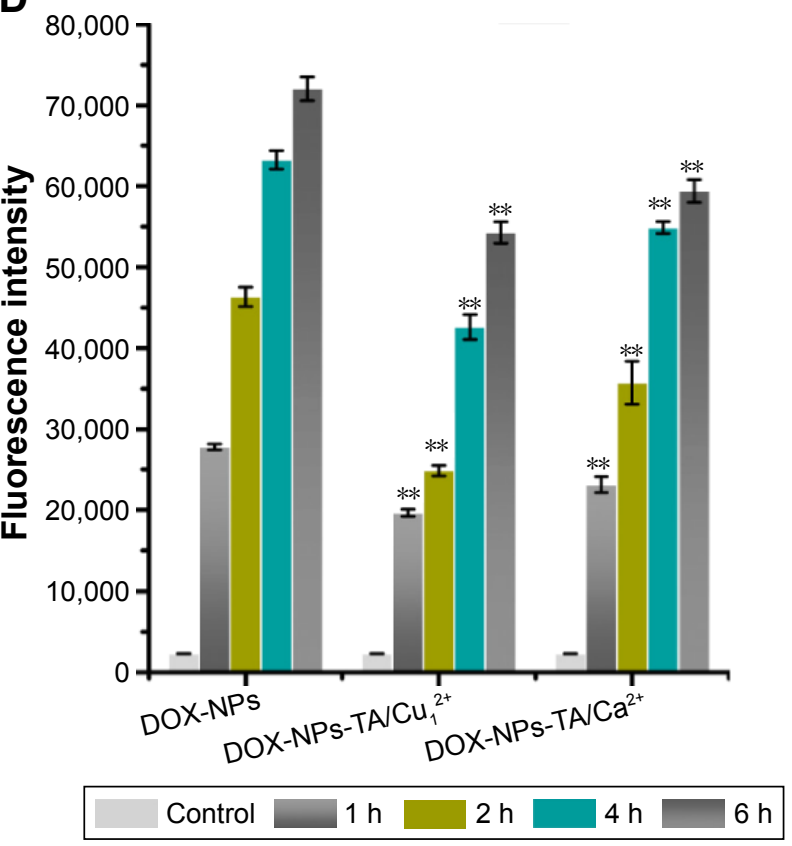

Figure 7 The qualitative (A-C) and quantitative (D) study of cellular uptake.

Notes: CLSM images of intracellular uptake of DOX-NPs (A), DOX-NPs-TA/Cu, ${ }_{1}{ }^{2+} \mathrm{NPs}(\mathbf{B})$ and DOX-NPs-TA/Ca ${ }^{2+} \mathrm{NPs}(\mathbf{C})$ by HepG2 cells. The scale bars represent $20 \mu \mathrm{m}$. Flow cytometry results of HepG2 cells as a function of time treated with DOX-loaded NPs (D). Data displayed as mean $\pm S D$ ( $n=3$ ). $* * P<0.0$ I versus the DOX-NPs group. Abbreviations: CLSM, confocal laser scanning microscopy; DOX, doxorubicin hydrochloride; NPs, nanoparticles; TA, tannic acid; SD, standard deviation.

effect of DOX in NPs. ${ }^{55,56}$ As shown in the CLSM image, the DOX could quickly release from the zein/CMCS NPs, consistent with drug release results. The dramatic decrease in fluorescence intensity was seen when DOX was loaded in $\mathrm{Cu}^{2+}$-TA-coated zein/CMCS NPs after $2 \mathrm{~h}$ of incubation (Figure 7B). When extending the time to $6 \mathrm{~h}$, the fluorescence intensity markedly increased in the cytoplasm, resulting from the release of DOX in acidic conditions. DOX-NPs-TA/ $\mathrm{Ca}^{2+}$ witnessed faster internalization of DOX inside the cells compared with DOX-NPs-TA/Cu ${ }^{2+}$ (Figure 7C). After $6 \mathrm{~h}$ of incubation, the fluorescence was disseminated in the cytoplasm. This result was consistent with the release results, and DOX-NPs-TA $/ \mathrm{Ca}^{2+}$ showed faster release rate than those coated with $\mathrm{Cu}^{2+}-\mathrm{TA}$ films. Flow cytometry measurements 
were further performed to quantify the results, which also revealed a consistent increase in the fluorescence intensity in HepG 2 cells when extending the incubation time (Figure 7D). As shown in Figure 7D, the mean DOX fluorescence intensity in HepG2 cells treated with DOX-NPs was higher than those incubated with DOX-NPs-TA/metal NPs. This result was the same as the CLSM results.

The cellular uptake results displayed that DOX-NPs-TA/ metal NPs would be internalized into the cells and partially release the drug because of the cleavage of coordination bonds.

\section{Conclusion}

We have demonstrated a biodegradable $\mathrm{pH}$-responsive film constructed into zein/CMCS NPs, which is based on the formation of coordination complexes between TA and metal ions. XPS analysis identified that the metals were incorporated into the NPs. The controlled release of anticancer drugs was tailored by $\mathrm{pH}$ values as well as the metal species and feeding concentrations. The cytotoxicity of blank NPs was found to be negligible but the DOX-loaded NPs exhibited a high cytotoxic activity against HepG2 cells. The cellular uptake results displayed that DOX-NPs-TA/metal NPs would be internalized into the cells and partially release the drug because of the cleavage of coordination bonds. This study on the design of a pH-responsive delivery system based on coordination bonding has provided a new insight for controlling the release of drug, exhibiting the potential application in antitumor therapies.

\section{Acknowledgments}

This work was financially supported by Ministry of Science and Technology of the People's Republic of China (program no 2016YFD0400804) and Hubei Provincial Science-technology Supporting Plan of China (no 2014BBB018). The authors greatly thank colleagues of Key Laboratory of Environment Correlative Dietology of Huazhong Agricultural University for offering many services.

\section{Disclosure}

The authors report no conflicts of interest in this work.

\section{References}

1. Ma Y, Zhou L, Zheng H, et al. pH-responsive mitoxantrone (MX) delivery using mesoporous silica nanoparticles (MSN). J Mater Chem. 2011;21(26):9483-9486.

2. Xing L, Zheng H, Cao Y, Che S. Coordination polymer coated mesoporous silica nanoparticles for $\mathrm{pH}$-responsive drug release. Adv Mater. 2012;24(48):6433-6437.
3. Somasundaram VH, Pillai R, Malarvizhi G, et al. Biodegradable radiofrequency responsive nanoparticles for augmented thermal ablation combined with triggered drug release in liver tumors. ACS Biomater Sci Eng. 2016;2(5):768-779.

4. Xu Z, Liu S, Kang Y, Wang M. Glutathione-responsive polymeric micelles formed by a biodegradable amphiphilic triblock copolymer for anticancer drug delivery and controlled release. ACS Biomater Sci Eng. 2015;1(7):585-592.

5. Zheng $\mathrm{H}$, Che S. Amino/quaternary ammonium groups bifunctionalized large pore mesoporous silica for $\mathrm{pH}$-responsive large drug delivery. RSC Adv. 2012;2(10):4421-4429.

6. Zheng H, Che S. Molecular design of coordination bonding architecture in mesoporous nanoparticles for rational $\mathrm{pH}$-responsive delivery. Microporous Mesoporous Mater. 2013;168:73-80.

7. Liang H, Zhou B, Li J, et al. Supramolecular design of coordination bonding architecture on zein nanoparticles for $\mathrm{pH}$-responsive anticancer drug delivery. Colloids Surf B Biointerfaces. 2015;136:1224-1233.

8. Li Q, Jin Y, Li M, Dong JX. Drug-loaded star-shaped $\mathrm{pH}$-responsive monomolecular copolymer nanocarriers for tumor targeting and cancer therapy. ACS Biomater Sci Eng. 2015;1(3):175-182.

9. Itagaki H, Koshino T, Ito T, Sano T, Ito D, Sugimura H. Volume phase transition of chemically cross-linked curdlan hydrogels dependent on pH. ACS Biomater Sci Eng. 2016;2(5):752-757.

10. Qiu Y, Park K. Environment-sensitive hydrogels for drug delivery. Adv Drug Del Rev. 2012;64:49-60.

11. Giammanco GE, Sosnofsky CT, Ostrowski AD. Light-responsive iron (III)-polysaccharide coordination hydrogels for controlled delivery. ACS Appl Mater Interfaces. 2015;7(5):3068-3076.

12. Chen X, Wang S, Lu M, et al. Formation and characterization of lightresponsive TEMPO-oxidized Konjac glucomannan microspheres. Biomacromolecules. 2014;15(6):2166-2171.

13. Strong LE, West JL. Hydrogel-coated near infrared absorbing nanoshells as light-responsive drug delivery vehicles. ACS Biomater Sci Eng. 2015; 1(8):685-692.

14. Zheng H, Gao C, Peng B, Shu M, Che S. pH-responsive drug delivery system based on coordination bonding in a mesostructured surfactant/ silica hybrid. J Phys Chem C. 2011;115(15):7230-7237.

15. Zheng H, Huang Z, Che S. Mesostructured chitosan-silica hybrid as a biodegradable carrier for a $\mathrm{pH}$-responsive drug delivery system. Dalton Trans. 2012;41(16):5038-5044.

16. Zheng H, Wang Y, Che S. Coordination bonding-based mesoporous silica for $\mathrm{pH}$-responsive anticancer drug doxorubicin delivery. $J$ Phys Chem C. 2011;115(34):16803-16813.

17. Zheng M, Liu S, Guan X, Xie Z. One-step synthesis of nanoscale zeolitic imidazolate frameworks with high curcumin loading for treatment of cervical cancer. ACS Appl Mater Interface. 2015;7(40):22181-22187.

18. Yang L, Li W, Kirberger M, Liao W, Ren J. Design of nanomaterial based systems for novel vaccine development. Biomater Sci. 2016;4(5): 785-802.

19. Yu Z, Cai Z, Chen Q, et al. Engineering $\beta$-sheet peptide assemblies for biomedical applications. Biomater Sci. 2016;4(3):365-374.

20. Liao W, Lu Y, Fu J, Ning Z, Yang J, Ren J. Preparation and characterization of dictyophora indusiata polysaccharide-zinc complex and its augmented antiproliferative activity on human cancer cells. J Agric Food Chem. 2015;63(29):6525-6534.

21. Lin L, Xu W, Liang H, et al. Construction of $\mathrm{pH}$-sensitive lysozyme/ pectin nanogel for tumor methotrexate delivery. Colloids Surf B Biointerfaces. 2015;126:459-466.

22. He L, Liang H, Lin L, et al. Green-step assembly of low density lipoprotein/sodium carboxymethyl cellulose nanogels for facile loading and $\mathrm{pH}$-dependent release of doxorubicin. Colloids Surf B Biointerfaces. 2015;126:288-296.

23. Xing L, Zheng H, Che S. A pH-responsive cleavage route based on a metalorganic coordination bond. Chemistry. 2011;17(26):7271-7275.

24. Rahim MA, Ejima H, Cho KL, et al. Coordination-driven multistep assembly of metal-polyphenol films and capsules. Chem Mater. 2014; 26(4):1645-1653. 
25. Costa E, Coelho M, Ilharco LM, Aguiar-Ricardo A, Hammond PT. Tannic acid mediated suppression of PNIPAAm microgels thermoresponsive behavior. Macromolecules. 2011;44(3):612-621.

26. Liang H, Li J, He Y, et al. Engineering multifunctional films based on metal-phenolic networks for rational $\mathrm{pH}$-responsive delivery and cell imaging. ACS Biomater Sci Eng. 2016;2(3):317-325.

27. Andjelković M, Van Camp J, De Meulenaer B, et al. Iron-chelation properties of phenolic acids bearing catechol and galloyl groups. Food Chem. 2006;98(1):23-31.

28. Guo J, Ping Y, Ejima H, et al. Engineering multifunctional capsules through the assembly of metal-phenolic networks. Angew Chem Int Ed Engl. 2014;53(22):5546-5551.

29. Zeng T, Zhang X, Guo Y, Niu H, Cai Y. Enhanced catalytic application of Au@ polyphenol-metal nanocomposites synthesized by a facile and green method. J Mater Chem A. 2014;2(36):14807-14811.

30. Ejima H, Richardson JJ, Liang K, et al. One-step assembly of coordination complexes for versatile film and particle engineering. Science. 2013;341(6142):154-157.

31. Ping Y, Guo J, Ejima H, et al. pH-responsive capsules engineered from metal-phenolic networks for anticancer drug delivery. Small. 2015; 11(17):2032-2036.

32. Luo Y, Teng Z, Wang Q. Development of zein nanoparticles coated with carboxymethyl chitosan for encapsulation and controlled release of vitamin D3. J Agric Food Chem. 2012;60(3):836-843.

33. Luo Y, Wang TT, Teng Z, Chen P, Sun J, Wang Q. Encapsulation of indole-3-carbinol and 3,3'-diindolylmethane in zein/carboxymethyl chitosan nanoparticles with controlled release property and improved stability. Food Chem. 2013;139(1):224-230.

34. Qiao H, Sun M, Su Z, et al. Kidney-specific drug delivery system for renal fibrosis based on coordination-driven assembly of catecholderived chitosan. Biomaterials. 2014;35(25):7157-7171.

35. Rahim MA, Kempe K, Müllner M, et al. Surface-confined amorphous films from metal-coordinated simple phenolic ligands. Chem Mater. 2015; 27(16):5825-5832.

36. Ju Y, Cui J, Müllner M, Suma T, Hu M, Caruso F. Engineering lowfouling and $\mathrm{pH}$-degradable capsules through the assembly of metalphenolic networks. Biomacromolecules. 2015;16(3):807-814.

37. Sileika TS, Barrett DG, Zhang R, Lau KHA, Messersmith PB. Colorless multifunctional coatings inspired by polyphenols found in tea, chocolate, and wine. Angew Chem Int Ed Engl. 2013;52(41):10766-10770.

38. Park JH, Kim K, Lee J, et al. A cytoprotective and degradable metalpolyphenol nanoshell for single-cell encapsulation. Angew Chem Int Ed Engl. 2014;53(46):12420-12425.

39. Luo Y, Teng Z, Wang TT, Wang Q. Cellular uptake and transport of zein nanoparticles: effects of sodium caseinate. J Agric Food Chem. 2013; 61(31):7621-7629.

40. Mourya VK, Inamdar NN, Tiwari A. Carboxymethyl chitosan and its applications. Adv Mat Lett. 2010;1(1):11-33.

41. Li KK, Yin SW, Yin YC, Tang CH, Yang XQ, Wen SH. Preparation of water-soluble antimicrobial zein nanoparticles by a modified antisolvent approach and their characterization. J Food Eng. 2013; 119(2):343-352
42. Çakar S, Özacar M. Fe-tannic acid complex dye as photo sensitizer for different morphological ZnO based DSSCs. Spectrochim Acta A Mol Biomol Spectrosc. 2016;163:79-88.

43. Peng C, Zhao Q, Gao C. Sustained delivery of doxorubicin by porous $\mathrm{CaCO}_{3}$ and chitosan/alginate multilayers-coated $\mathrm{CaCO}_{3}$ microparticles. Colloids Surf A Physicochem Eng Asp. 2010;353(2):132-139.

44. Weng L, Le HC, Lin J, Golzarian J. Doxorubicin loading and eluting characteristics of bioresorbable hydrogel microspheres: in vitro study. Int J Pharm. 2011;409(1):185-193.

45. Li C, Xing L, Che S. Coordination bonding based $\mathrm{pH}$-responsive albumin nanoparticles for anticancer drug delivery. Dalton Trans. 2012; 41(13):3714-3719.

46. Jin D, Lee JH, Seo ML, Jaworski J, Jung JH. Controlled drug delivery from mesoporous silica using a $\mathrm{pH}$-response release system. New J Chem. 2012;36(8):1616.

47. Gao C, Zheng H, Xing L, Shu M, Che S. Designable coordination bonding in mesopores as a pH-responsive release system. Chem Mater. 2010; 22(19):5437-5444.

48. Xie M, Shi H, Ma K, et al. Hybrid nanoparticles for drug delivery and bioimaging: mesoporous silica nanoparticles functionalized with carboxyl groups and a near-infrared fluorescent dye. J Colloid Interface Sci. 2013;395:306-314.

49. Shutava T, Prouty M, Kommireddy D, Lvov Y. pH responsive decomposable layer-by-layer nanofilms and capsules on the basis of tannic acid. Macromolecules. 2005;38(7):2850-2858.

50. Gou P, Liu W, Mao W, Tang J, Shen Y, Sui M. Self-assembling doxorubicin prodrug forming nanoparticles for cancer chemotherapy: synthesis and anticancer study in vitro and in vivo. J Mater Chem B. 2013;1(3):284-292.

51. Chen KJ, Chiu YL, Chen YM, Ho YC, Sung HW. Intracellularly monitoring/imaging the release of doxorubicin from $\mathrm{pH}$-responsive nanoparticles using Förster resonance energy transfer. Biomaterials. 2011;32(10):2586-2592.

52. He H, Chen S, Zhou J, et al. Cyclodextrin-derived pH-responsive nanoparticles for delivery of paclitaxel. Biomaterials. 2013;34(21): 5344-5358.

53. Liang H, Huang Q, Zhou B, et al. Self-assembled zein-sodium carboxymethyl cellulose nanoparticles as an effective drug carrier and transporter. J Mater Chem B. 2015;3(16):3242-3253.

54. Zhang TT, Yang L, Jiang JG. Effects of thonningianin A in natural foods on apoptosis and cell cycle arrest of HepG-2 human hepatocellular carcinoma cells. Food Funct. 2015;6(8):2588-2597.

55. Zheng H, Li S, Pu Y, Lai Y, He B, Gu Z. Nanoparticles generated by PEG-chrysin conjugates for efficient anticancer drug delivery. Eur $J$ Pharm Biopharm. 2014;87(3):454-460.

56. Jin R, Ji X, Yang Y, Wang H, Cao A. Self-assembled graphene-dextran nanohybrid for killing drug-resistant cancer cells. ACS Appl Mater Interfaces. 2013;5(15):7181-7189. 


\section{Supplementary materials}

Table SI Characterization of NPs (pH 7.4)

\begin{tabular}{llll}
\hline Samples & Size, $\mathbf{n m}$ & PDI & Zeta potential, mV \\
\hline $\mathrm{Z}_{2} / \mathrm{CMCS}{ }_{1}$ & $100.3 \pm 2.2$ & $0.14 \pm 0.02$ & $-24.3 \pm 0.7$ \\
$\mathrm{Z}_{2} / \mathrm{CMCS}_{1}-\mathrm{TA} / \mathrm{Cu}_{1}{ }^{2+}$ & $108.3 \pm 3.5$ & $0.12 \pm 0.02$ & $-32.7 \pm 2.2$ \\
$\mathrm{Z}_{2} / \mathrm{CMCS}_{1}-\mathrm{TA} / \mathrm{Cu}_{2}{ }^{2+}$ & $116.1 \pm 2.2$ & $0.16 \pm 0.01$ & $-31.0 \pm 1.5$ \\
$\mathrm{Z}_{2} / \mathrm{CMCS}_{1}-\mathrm{TA} / \mathrm{Cu}_{3}{ }^{2+}$ & $122.2 \pm 3.3$ & $0.25 \pm 0.02$ & $-32.1 \pm 1.6$ \\
$\mathrm{Z}_{2} / \mathrm{CMCS}_{1}-\mathrm{TA} / \mathrm{Ca}^{2+}$ & $129.4 \pm 2.3$ & $0.20 \pm 0.01$ & $-25.4 \pm 0.3$ \\
\hline
\end{tabular}

Notes: The results displayed as mean \pm standard deviation $(n=3)$. The NPs were prepared at a zein:CMCS ratio of 2:I w/w with the final metal ion concentration of $0.24 \mathrm{mM}$ $\left(\mathrm{Cu}_{1}{ }^{2+}\right.$ or $\left.\mathrm{Ca}^{2+}\right), 0.48 \mathrm{mM}\left(\mathrm{Cu}_{2}{ }^{2+}\right)$ and $0.72 \mathrm{mM}\left(\mathrm{Cu}_{3}^{2+}\right)$.

Abbreviations: CMCS, carboxymethyl chitosan; NPs, nanoparticles; PDI, polydispersity index; TA, tannic acid; $\mathrm{Z}_{2}$, zein ${ }_{2}$.

Table S2 Characterization of NPs (pH 7.4)

\begin{tabular}{llll}
\hline Samples & Size, $\mathbf{n m}$ & PDI & Zeta potential, mV \\
\hline $\mathrm{Z}_{1} / \mathrm{CMCS}{ }_{1}$ & $82.1 \pm 1.6$ & $0.15 \pm 0.01$ & $-24.6 \pm 1.9$ \\
$\mathrm{Z}_{1} / \mathrm{CMCS}_{1}-\mathrm{TA} / \mathrm{Cu}_{1}{ }^{2+}$ & $96.6 \pm 2.7$ & $0.19 \pm 0.01$ & $-31.9 \pm 5.1$ \\
$\mathrm{Z}_{1} / \mathrm{CMCS}_{1}-\mathrm{TA} / \mathrm{Cu}_{2}{ }^{2+}$ & $1 \mathrm{l} 14.5 \pm 1.3$ & $0.17 \pm 0.02$ & $-32.2 \pm 1.2$ \\
$\mathrm{Z}_{1} / \mathrm{CMCS}_{1}-\mathrm{TA} / \mathrm{Cu}_{3}{ }^{2+}$ & $118.3 \pm 2.8$ & $0.26 \pm 0.01$ & $-30.0 \pm 2.0$ \\
$\mathrm{Z}_{1} / \mathrm{CMCS}_{1}-\mathrm{TA}^{2+} / \mathrm{Ca}^{2+}$ & $90.1 \pm 0.4$ & $0.21 \pm 0.01$ & $-27.9 \pm 2.4$ \\
\hline
\end{tabular}

Notes: The results displayed as mean \pm standard deviation $(n=3)$. The NPs were prepared at a zein:CMCS ratio of I:I w/w with the final metal ion concentration of $0.24 \mathrm{mM}$ $\left(\mathrm{Cu}_{1}{ }^{2+}\right.$ or $\left.\mathrm{Ca}^{2+}\right), 0.48 \mathrm{mM}\left(\mathrm{Cu}_{2}{ }^{2+}\right)$ and $0.72 \mathrm{mM}\left(\mathrm{Cu}_{3}{ }^{2+}\right)$.

Abbreviations: CMCS, carboxymethyl chitosan; NPs, nanoparticles; PDI, polydispersity index; TA, tannic acid; $Z_{1}$, zein, .

Table S3 Characterization of NPs (pH 7.4)

\begin{tabular}{llll}
\hline Samples & Size, $\mathbf{n m}$ & PDI & Zeta potential, mV \\
\hline $\mathrm{Z}_{1} / \mathrm{CMCS}_{2}$ & $103.3 \pm 0.6$ & $0.17 \pm 0.01$ & $-27.8 \pm 1.8$ \\
$\mathrm{Z}_{1} / \mathrm{CMCS}_{2}-\mathrm{TA} / \mathrm{Cu}_{1}{ }^{2+}$ & $113.3 \pm 1.9$ & $0.25 \pm 0.01$ & $-32.0 \pm 1.4$ \\
$\mathrm{Z}_{1} / \mathrm{CMCS}_{2}-\mathrm{TA}_{\mathrm{CCa}}{ }^{2+}$ & $89.3 \pm 1.1$ & $0.17 \pm 0.01$ & $-29.4 \pm 0.6$ \\
\hline
\end{tabular}

Notes: The results displayed as mean \pm standard deviation $(n=3)$. The NPs were prepared at a zein:CMCS ratio of $\mathrm{I}: 2 \mathrm{w} / \mathrm{w}$ with the final metal ion concentration of $0.24 \mathrm{mM}$ $\left(\mathrm{Cu}_{1}{ }_{1}^{2+}\right.$ or $\left.\mathrm{Ca}^{2+}\right)$.

Abbreviations: CMCS, carboxymethyl chitosan; NPs, nanoparticles; PDI, polydispersity index; TA, tannic acid; $Z_{1}$, zein,

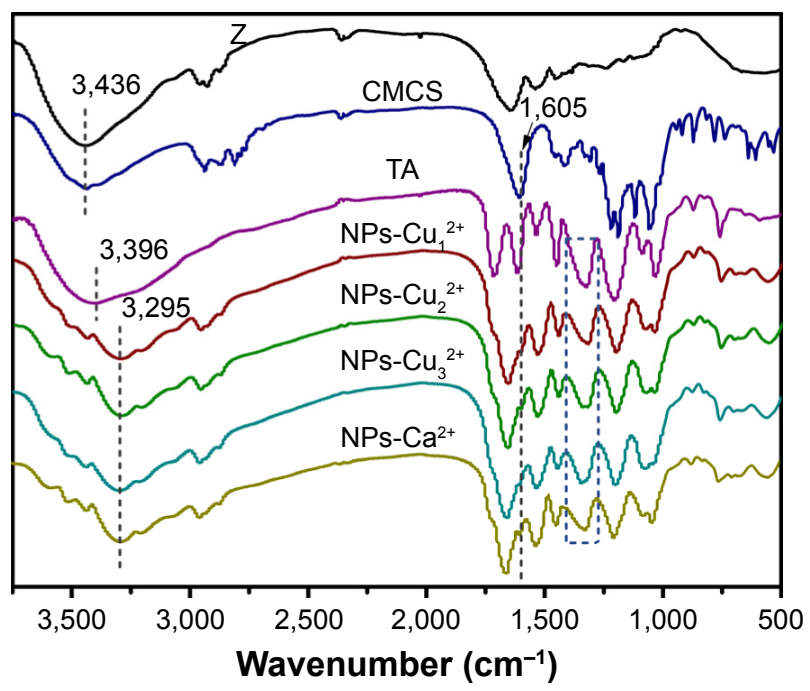

Figure SI Fourier transform infrared spectroscopy (FTIR) spectra of different samples.

Notes: NPs-Cu ${ }_{1}^{2+}, \mathrm{NPs}_{-} \mathrm{Cu}_{2}{ }^{2+}, \mathrm{NPs}-\mathrm{Cu}_{3}{ }^{2+}, \mathrm{NPs}-\mathrm{Ca}^{2+}$ : metal-TA-coated zein/CMCS nanoparticles prepared at a zein:CMCS ratio of I:I w/w with the final metal ion concentration of $0.24 \mathrm{mM}\left(\mathrm{Cu}_{1}{ }^{2+}\right.$ or $\left.\mathrm{Ca}^{2+}\right), 0.48 \mathrm{mM}\left(\mathrm{Cu}_{2}{ }^{2+}\right)$ and $0.72 \mathrm{mM}\left(\mathrm{Cu}_{3}{ }^{2+}\right)$.

Abbreviations: CMCS, carboxymethyl chitosan; NPs, nanoparticles; TA, tannic acid. 

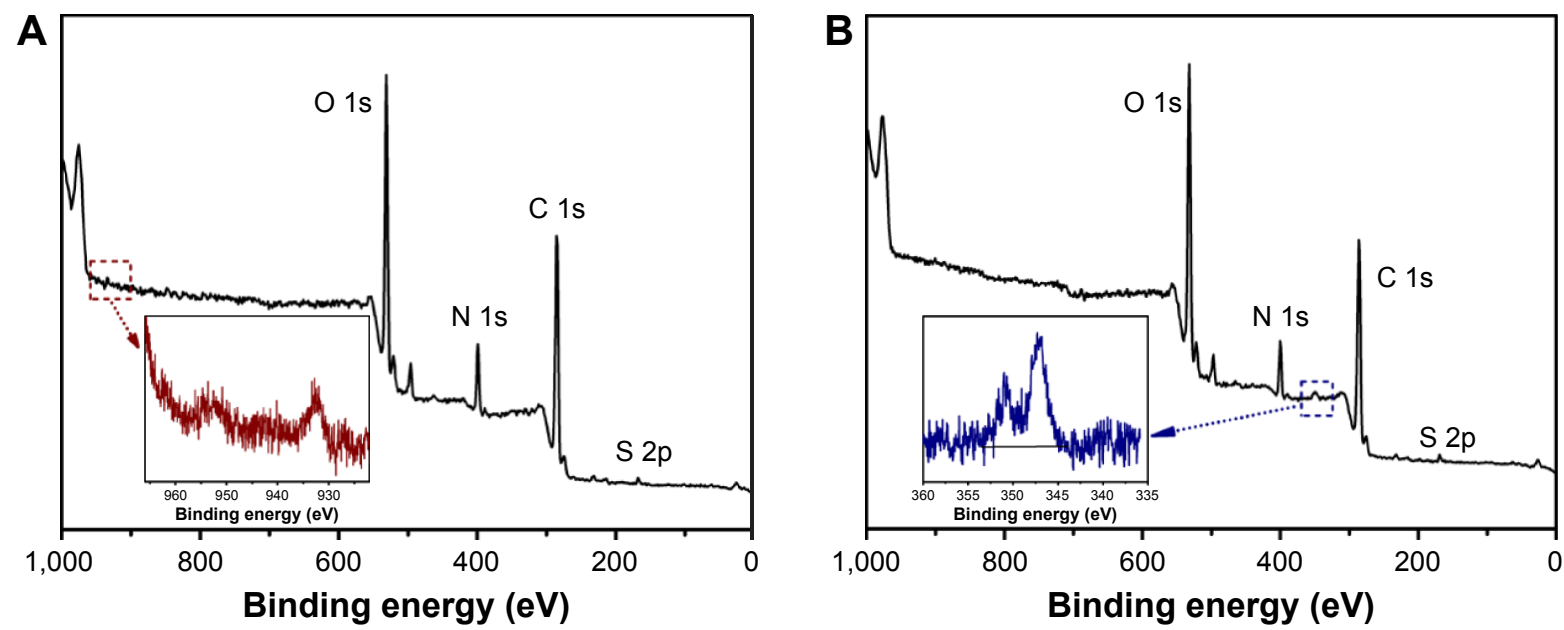

Figure S2 XPS survey spectra of $Z_{1} / \mathrm{CMCS}_{1}-\mathrm{TA} / \mathrm{Cu}_{1}^{2+}(\mathbf{A})$ and $\mathrm{Z}_{1} / \mathrm{CMCS}_{1}-\mathrm{TA} / \mathrm{Ca}^{2+}(\mathbf{B})$.

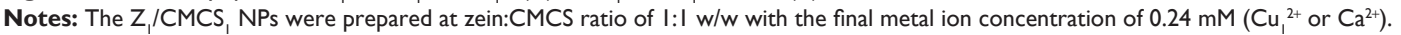

Abbreviations: CMCS, carboxymethyl chitosan; TA, tannic acid; XPS, X-ray photoelectron spectroscopy; $Z_{1}$, zein

Table S4 Element composition and content on the surface of $Z_{1} / \mathrm{CMCS}_{1}-\mathrm{TA} / \mathrm{Cu}_{1}{ }^{2+} \mathrm{NPs}$ and $\mathrm{Z}_{1} / \mathrm{CMCS}_{1}-\mathrm{TA} / \mathrm{Ca}^{2+} \mathrm{NPs}$

\begin{tabular}{lllllll}
\hline Sample & $\mathbf{C}$ & $\mathbf{O}$ & $\mathbf{N}$ & $\mathbf{S}$ & $\mathbf{C u}$ & $\mathbf{C a}$ \\
\hline $\mathrm{Z}_{1} / \mathrm{CMCS}_{1}-\mathrm{TA} / \mathrm{Cu}_{1}{ }^{2+}$ & 64.33 & 25.45 & 8.85 & 1.14 & 0.23 & - \\
$\mathrm{Z}_{1} / \mathrm{CMCS}_{1}-\mathrm{TA}^{2} / \mathrm{Ca}^{2+}$ & 62.85 & 27.04 & 8.54 & 1.09 & - & 0.48 \\
\hline
\end{tabular}

Note: '-' indicates element not detected.

Abbreviations: CMCS, carboxymethyl chitosan; NPs, nanoparticles; TA, tannic acid; $Z_{1}$, zein .

Table S5 Characterization of DOX-loaded NPs ( $\mathrm{pH} 7.4)$

\begin{tabular}{lllll}
\hline Samples & Size, $\mathbf{n m}$ & PDI & $\begin{array}{l}\text { Zeta potential, } \\
\mathbf{m V}\end{array}$ & $\begin{array}{l}\text { Encapsulation } \\
\text { efficiency, \% }\end{array}$ \\
\hline DOX-Z,/CMCS, & $135.2 \pm 1.2$ & $0.18 \pm 0.01$ & $-24.5 \pm 0.7$ & $91.0 \pm 0.9$ \\
DOX-Z,/CMCS, $-\mathrm{TA} / \mathrm{Cu}_{1}{ }_{1}{ }^{2+}$ & $140.6 \pm 1.6$ & $0.23 \pm 0.01$ & $-32.7 \pm 0.3$ & $96.1 \pm 1.1$ \\
DOX-Z,/CMCS, $-\mathrm{TA} / \mathrm{Cu}_{2}{ }^{2+}$ & $144.3 \pm 2.0$ & $0.21 \pm 0.03$ & $-33.2 \pm 0.4$ & $95.9 \pm 0.8$ \\
DOX-Z,/CMCS, $-\mathrm{TA} / \mathrm{Cu}_{3}{ }^{2+}$ & $160.1 \pm 4.3$ & $0.27 \pm 0.02$ & $-32.2 \pm 0.4$ & $96.4 \pm 0.7$ \\
DOX-Z, /CMCS, $-\mathrm{TA} / \mathrm{Ca}^{2+}$ & $137.6 \pm 2.1$ & $0.21 \pm 0.02$ & $-28.1 \pm 0.8$ & $93.4 \pm 1.3$ \\
\hline
\end{tabular}

Notes: The results displayed as mean \pm standard deviation $(n=3)$. The NPs were prepared at a zein:CMCS ratio of I:I w/w with the final metal ion concentration of $0.24 \mathrm{mM}$ $\left(\mathrm{Cu}_{1}{ }^{2+}\right.$ or $\left.\mathrm{Ca}^{2+}\right), 0.48 \mathrm{mM}\left(\mathrm{Cu}_{2}^{2+}\right)$ and $0.72 \mathrm{mM}\left(\mathrm{Cu}_{3}^{2+}\right)$.

Abbreviations: CMCS, carboxymethyl chitosan; DOX, doxorubicin hydrochloride; NPs, nanoparticles; TA, tannic acid; $Z_{1}$, zein .

Table S6 Characterization of DOX-loaded NPs ( $\mathrm{pH} 7.4)$

\begin{tabular}{|c|c|c|c|}
\hline Samples & Size, nm & PDI & Zeta potential, $\mathrm{mV}$ \\
\hline $\mathrm{DOX}-\mathrm{Z}_{1} / \mathrm{CMCS}_{2}$ & $130.8 \pm 1.6$ & $0.17 \pm 0.02$ & $-27.3 \pm 0.9$ \\
\hline DOX-Z, $/ \mathrm{CMCS}_{2}-\mathrm{TA} / \mathrm{Cu}_{1}{ }^{2+}$ & $136.7 \pm 1.8$ & $0.26 \pm 0.01$ & $-32.3 \pm 0.7$ \\
\hline DOX-Z, $/ \mathrm{CMCS}_{2}-\mathrm{TA} / \mathrm{Ca}^{2+}$ & $128.1 \pm 1.1$ & $0.22 \pm 0.01$ & $-32.0 \pm 0.8$ \\
\hline
\end{tabular}

Notes: The results displayed as mean \pm standard deviation $(n=3)$. The NPs were prepared at a zein:CMCS ratio of $\mathrm{I}: 2 \mathrm{w} / \mathrm{w}$ with the final metal ion concentration of $0.24 \mathrm{mM}$ $\left(\mathrm{Cu}_{1}{ }^{2+}\right.$ or $\left.\mathrm{Ca}^{2+}\right)$.

Abbreviations: CMCS, carboxymethyl chitosan; DOX, doxorubicin hydrochloride; NPs, nanoparticles; TA, tannic acid; $Z_{1}$, zein . 
Table S7 Characterization of DOX-loaded NPs ( $\mathrm{pH} 7.4)$

\begin{tabular}{|c|c|c|c|}
\hline Samples & Size, $\mathbf{n m}$ & PDI & Zeta potential, $\mathrm{mV}$ \\
\hline $\mathrm{DOX}-\mathrm{Z}_{2} / \mathrm{CMCS}_{1}$ & $156.4 \pm 4.9$ & $0.15 \pm 0.01$ & $-23.0 \pm 1.7$ \\
\hline $\mathrm{DOX}-\mathrm{Z}_{2} / \mathrm{CMCS}_{1}-\mathrm{TA} / \mathrm{Cu}_{1}{ }^{2+}$ & $156.8 \pm 3.5$ & $0.23 \pm 0.02$ & $-32.9 \pm 0.6$ \\
\hline $\mathrm{DOX}-\mathrm{Z}_{2} / \mathrm{CMCS}_{1}-\mathrm{TA} / \mathrm{Cu}_{2}{ }^{2+}$ & $165.5 \pm 3.6$ & $0.26 \pm 0.01$ & $-37.7 \pm 1.4$ \\
\hline DOX $-\mathrm{Z}_{2} / \mathrm{CMCS}_{1}-\mathrm{TA} / \mathrm{Cu}_{3}{ }^{2+}$ & $181.7 \pm 3.8$ & $0.26 \pm 0.01$ & $-37.4 \pm 1.3$ \\
\hline DOX-Z $Z_{2} / \mathrm{CMCS}_{1}-\mathrm{TA} / \mathrm{Ca}^{2+}$ & $172.4 \pm 3.7$ & $0.20 \pm 0.01$ & $-27.6 \pm 0.7$ \\
\hline
\end{tabular}

Notes: The results displayed as mean \pm standard deviation $(n=3)$. The NPs were prepared at a zein:CMCS ratio of $2: 1 \mathrm{w} / \mathrm{w}$ with the final metal ion concentration of $0.24 \mathrm{mM}$ $\left(\mathrm{Cu}_{1}{ }^{2+}\right.$ or $\left.\mathrm{Ca}^{2+}\right), 0.48 \mathrm{mM}\left(\mathrm{Cu}_{2}{ }^{2+}\right)$ and $0.72 \mathrm{mM}\left(\mathrm{Cu}_{3}{ }^{2+}\right)$.

Abbreviations: CMCS, carboxymethyl chitosan; DOX, doxorubicin hydrochloride; NPs, nanoparticles; TA, tannic acid; $Z_{2}$, zein ${ }_{2}$.

Table S8 IC s0 values for DOX-loaded NPs against HepG2 cells

\begin{tabular}{|c|c|c|}
\hline Samples & Cell & $I C_{50}(\mu \mathrm{g} / \mathrm{mL})$ \\
\hline $\mathrm{DOX}-\mathrm{Z}_{1} / \mathrm{CMCS}_{1}$ & HepG2 & $2.36 \pm 0.18$ \\
\hline $\mathrm{DOX}-\mathrm{Z}_{1} / \mathrm{CMCS}_{1}-\mathrm{TA} / \mathrm{Cu}_{1}{ }^{2+}$ & HepG2 & $2.91 \pm 0.12 *$ \\
\hline DOX $-Z_{1} / \mathrm{CMCS}_{1}-\mathrm{TA} / \mathrm{Ca}^{2+}$ & HepG2 & $2.67 \pm 0.28$ \\
\hline
\end{tabular}

Notes: The results displayed as mean \pm standard deviation $(n=3)$. $* P<0.05$ versus DOX-Z, /CMCS, group. The NPs were prepared at zein:CMCS ratio of I:I w/w with the final metal ion concentration of $0.24 \mathrm{mM}\left(\mathrm{Cu}_{1}{ }_{1}^{2+}\right.$ or $\left.\mathrm{Ca}^{2+}\right)$.

Abbreviations: CMCS, carboxymethyl chitosan; DOX, doxorubicin hydrochloride; $\mathrm{IC}_{50}$, half maximal inhibitory concentration; NPs, nanoparticles; TA, tannic acid; $Z_{1}$, zein ${ }_{1}$.

\section{Publish your work in this journal}

The International Journal of Nanomedicine is an international, peerreviewed journal focusing on the application of nanotechnology in diagnostics, therapeutics, and drug delivery systems throughout the biomedical field. This journal is indexed on PubMed Central, MedLine, CAS, SciSearch ${ }^{\circledR}$, Current Contents ${ }^{\circledR} /$ Clinical Medicine,
Journal Citation Reports/Science Edition, EMBase, Scopus and the Elsevier Bibliographic databases. The manuscript management system is completely online and includes a very quick and fair peer-review system, which is all easy to use. Visit http://www.dovepress.com/ testimonials.php to read real quotes from published authors. 